\title{
The Relationship between Land-Ocean Surface Temperature Contrast and Radiative Forcing
}

\author{
F. Hugo LAMBERT* AND MARK J. WebB
}

Met Office Hadley Centre, Exeter, United Kingdom

MANOJ M. JOSHI

National Centre for Atmospheric Science-Climate, Department of Meteorology, University of Reading, Reading, United Kingdom

(Manuscript received 15 June 2010, in final form 13 October 2010)

\begin{abstract}
Previous work has demonstrated that observed and modeled climates show a near-time-invariant ratio of mean land to mean ocean surface temperature change under transient and equilibrium global warming. This study confirms this in a range of atmospheric models coupled to perturbed sea surface temperatures (SSTs), slab (thermodynamics only) oceans, and a fully coupled ocean. Away from equilibrium, it is found that the atmospheric processes that maintain the ratio cause a land-to-ocean heat transport anomaly that can be approximated using a two-box energy balance model. When climate is forced by increasing atmospheric $\mathrm{CO}_{2}$ concentration, the heat transport anomaly moves heat from land to ocean, constraining the land to warm in step with the ocean surface, despite the small heat capacity of the land. The heat transport anomaly is strongly related to the top-of-atmosphere radiative flux imbalance, and hence it tends to a small value as equilibrium is approached. In contrast, when climate is forced by prescribing changes in SSTs, the heat transport anomaly replaces "missing" radiative forcing over land by moving heat from ocean to land, warming the land surface. The heat transport anomaly remains substantial in steady state. These results are consistent with earlier studies that found that both land and ocean surface temperature changes may be approximated as local responses to global mean radiative forcing. The modeled heat transport anomaly has large impacts on surface heat fluxes but small impacts on precipitation, circulation, and cloud radiative forcing compared with the impacts of surface temperature change. No substantial nonlinearities are found in these atmospheric variables when the effects of forcing and surface temperature change are added.
\end{abstract}

\section{Introduction}

The near-time-invariant ratio of annual global mean land surface temperature change to global mean ocean surface temperature change $\phi$ is a robust feature of observed and modeled climate change and variability (Manabe et al. 1991; Huntingford and Cox 2000; Sutton et al. 2007; Lambert and Chiang 2007, hereafter LC07). With respect to preindustrial conditions, the land warms $30 \%-70 \%$ more than the ocean in both observations and

* Current affiliation: University of Exeter, Exeter, United Kingdom.

Corresponding author address: F. Hugo Lambert, College of Engineering, Mathematics and Physical Sciences, University of Exeter, Harrison Building, North Park Road, Exeter EX4 4QF, United Kingdom.

E-mail: f.h.lambert@exeter.ac.uk general circulation model (GCM) experiments. This is largely because of the different surface and atmospheric feedbacks that occur over the land compared with the ocean, rather than because of the different distributions of land and ocean in latitude (Sutton et al. 2007; Joshi et al. 2008, hereafter JGW08; Compo and Sardeshmukh 2009, hereafter CS09). Current GCMs appear to capture the observed ratio of mean land to mean ocean surface warming quite well (LC07), although newer work indicates that including physiological dependencies of vegetation on atmospheric $\mathrm{CO}_{2}$ concentration in a GCM has a significant impact on land temperature. Rapid cloud changes induced by stomatal closure in response to increases in $\mathrm{CO}_{2}$ concentration tend to cause further warming (JGW08; Joshi and Gregory 2008; Doutriaux-Boucher et al. 2009).

Despite the effective heat capacity of the ocean being much larger than that of the land, values of $\phi$ are similar for transient and equilibrium climate change. This is not 
too surprising when we consider that, in a given GCM, perturbed climates relax strongly toward a similar value of $\phi$ under a variety of very different scenarios. For example, if a coupled atmosphere-ocean GCM is perturbed by applying a radiative forcing, then we can calculate a value of $\phi$ based on the land and ocean surface temperature anomalies at the new equilibrium. If the same GCM is perturbed by imposing an ocean surface temperature anomaly, we find that land temperatures rapidly adjust to produce a similar value of $\phi$ to the radiatively coupled forced experiment (CS09; Dommenget 2009, hereafter D09). Conversely, if a radiative forcing is applied to the GCM but ocean surface temperatures are fixed at control values, the land temperature will increase only very slightly (Hansen et al. 2002) (this is a "Hansen" experiment; see section 3). Clearly, $\phi$ is not defined in the last case, as ocean surface temperature change is zero. The point is that the modeled climate system land and ocean temperatures tend to change together, rather than independently of one another. This tendency is also apparent in the observations. Despite rapid variations in radiative forcing, LC07 found that observed land and ocean surface temperatures since 1945 stayed at least as close to a constant ratio as simulations of the same period from seven fully coupled atmosphere-ocean GCMs.

This behavior has led CS09 and D09 to propose that observed land warming is predominantly caused by ocean warming, and that the direct effects of radiative forcing over land are of less importance. However, there are also GCM experiments in which radiative forcing is applied over land-only that relax toward a value of $\phi$ consistent with that found when radiative forcing is globally uniform. These and other GCM experiments with various spatially inhomogeneous distributions of forcing have established an alternative picture whereby land and ocean mean surface temperature changes are approximated as local responses to global mean forcing (Forster et al. 2000; Boer and Yu 2003; Joshi et al. 2003). Finally, there is at least one GCM experiment in which an imposed land temperature anomaly has almost no effect on ocean surface temperatures (D09).

In this paper, we explore the relationships between land and ocean surface temperature changes and top-ofatmosphere (TOA) radiation balance in a series of idealized GCM experiments. LC07 suggested that surface temperature changes or radiative forcings that tend to take the climate system away from constant $\phi$ are opposed by processes that result in a net heat transport anomaly between land and ocean surfaces. Their hypothesis was that the heat transport is sufficient to keep land and ocean temperature anomalies much nearer to a time-invariant $\phi$, than would be found otherwise. This appears sensible when we consider that large atmospheric heat transports exist in the background climatic mean state and seasonal cycle. Mean meridional atmospheric heat transports move on the order of $100 \mathrm{~W} \mathrm{~m}^{-2}$ poleward, significantly decreasing the equator-to-pole temperature gradient (e.g., Trenberth and Solomon 1994; Fasullo and Trenberth 2008b); land-ocean heat transports ensure that the vast majority of heat taken up by the climate system during the annual cycle is absorbed by the ocean (e.g., Ellis et al. 1978; Shin et al. 2006). Of course, the ratio of land to ocean surface temperature anomalies in the seasonal cycle is not constant. Land and ocean surface temperatures are nearer to $\pi / 2$ out of phase with one another because of the land being in the Northern Hemisphere (Ellis et al. 1978; Shin et al.2006). It must be said also that there are considerable land-ocean interactions in the mean state that are not conducted by heat transports but by "nonenergetic teleconnections." Notably, a large portion of the water vapor present over land is evaporated from the ocean (e.g., Trenberth et al. 2007). Water vapor aloft affects land temperatures by affecting atmospheric radiation. This is not a land-ocean heat transport, however, as changes in heat fluxes at the land surface do not originate from the ocean surface but in the atmosphere over land. (There is a heat flux associated with surplus ocean evaporationprecipitation compared with land evaporation-precipitation, but this is not the direct cause of the greenhouse effect over land.)

We investigate the land-ocean heat transport anomaly, its predictability using the equations of $\mathrm{LC} 07$, and related impacts at the surface and in the atmosphere aloft. We find that the heat transport is a useful diagnostic for comparing the views of CS09 and D09 with those of Forster et al. (2000), Boer and Yu (2003), and Joshi et al. (2003). The paper is arranged as follows: section 2 reviews mechanisms that have been proposed to explain the relation between land and ocean surface temperature change, section 3 introduces the GCM data that we use, section 4 tests the mechanisms discussed in section 2 and describes impacts on surface and atmospheric variables, section 5 presents a discussion of the results, and section 6 is a summary.

\section{Mechanisms proposed to explain land-ocean temperature contrast}

In this section, we review the processes proposed to control the relationship between perturbations in land and ocean surface temperature contrast at equilibrium and during transient climate change. Note that, when we say surface temperatures, we are always referring to $1.5 \mathrm{~m}$ of air temperature. When we say radiative forcing, we always mean the adjusted or "effective" forcing that can be diagnosed from regressing annual mean TOA radiation 
anomalies against annual mean surface temperature anomalies (Gregory et al. 2004; Hansen et al. 2005). Finally, we assume that the effects of forcings and feedbacks on surface and TOA fluxes are separable and hence that the climate feedbacks we discuss are independent of the source of radiative forcing applied (Forster et al. 2000; Boer and Yu 2003; Joshi et al. 2003; Hansen et al. 2005).

\section{a. Equilibrium land-ocean surface temperature contrast}

Three nonmutually exclusive processes that control equilibrium $\phi$ have been described by previous work.

(i) An increase in net downward surface radiation caused by the response to an increase in greenhouse gas concentration or other radiative forcing on climate is largely compensated for by an increase in latent heat flux over the ocean. Over many land areas, however, latent heat fluxes are unable to keep pace with changes in surface radiative fluxes as the land dries out. Increases in upward sensible heat flux are therefore relatively more important over land than over ocean. As a result, the land must warm more than the ocean to balance imposed radiative forcing (Manabe et al. 1991; Sutton et al. 2007; Dong et al. 2009).

(ii) Atmospheric processes cause additional land surface warming relative to the ocean. In the mid- and upper troposphere, climatic anomalies due to surface warming are zonally quite uniform because of efficient atmospheric transport. Below about $700 \mathrm{hPa}$, however, there are differences between land and ocean lapse rates, related to the larger proportion of saturated atmospheric profiles found over ocean. Saturation specific humidity increases approximately exponentially with increasing temperature, causing the saturated adiabatic lapse rate to decrease with increasing temperature. The dry adiabatic lapse rate, meanwhile, remains almost the same as the temperature increases. Hence, in a warmer climate, oceanic lapse rates will tend to decrease with respect to land lapse rates. Temperature anomalies in the free oceanic troposphere, which warms more quickly than the surface because of the decreasing lapse rate, are then communicated to the land surface. Because lapse rates over land are greater than over ocean, the land surface temperature (LST) change that results from tropospheric warming is greater than the sea surface temperature (SST) change (JGW08).

(iii) Changes in atmospheric moisture convergence lead to land surface drying and further land warming. Net atmospheric convergence transports moisture from ocean to land where it falls as precipitation. Given that relative humidity remains quite constant under modeled climate change, specific humidity increases more rapidly at the surface than in the midtroposphere as the earth warms. However, because the bulk of atmospheric convergence occurs above the boundary layer at a colder temperature than the surface, air imported from the ocean to the land carries a smaller proportion of the moisture required to maintain constant relative humidity near the land surface. This occurs even though the midtroposphere warms more than the land surface because of the strong nonlinearity of the Clausius-Clapeyron equation with temperature. As a result, land evaporation initially increases to compensate, but the land surface quickly begins to dry out, leading to further land warming (JGW08). The lifting condensation level moves to higher altitude and the energetic threshold for convective initiation increases. Related cloud and humidity feedbacks increase anomalous outgoing longwave radiation (Fasullo 2010).

The mechanisms that communicate oceanic tropospheric warming to land are different in the tropics and midlatitudes. In the tropics, the atmosphere is unable to maintain strong tropospheric temperature gradients because of the weakness of the Coriolis parameter. Climate anomalies in one region are shared rapidly with the global tropical atmosphere by tropospheric wave activity, before being transmitted to the surface by radiative and evaporative feedbacks (Brown and Bretherton 1997; Chiang and Sobel 2002) (the mechanism is least effective in regions of large scale descent, where the surface is more isolated from the free atmosphere). Outside the tropics, the atmosphere can maintain larger temperature gradients through geostrophic balance. However, air masses move between ocean and land, and can communicate their temperature and moisture characteristics to the surface during "surface modification" (e.g., Curry and Webster 1999).

In the above, we have emphasized the effect of the ocean on land climate change. The processes can be traced in the opposite direction, meaning that we also expect a land effect on ocean climate change. However, because land covers less then a third of the earth's surface, we expect the effect of the ocean on land climate change to be larger. Indeed, D09 found that the effect of ocean on land is still larger than the effect of land on ocean when the relative surface areas of ocean and land are taken into account (although refer to a discussion of D09's fixed LST GCM experiments in section 5).

\section{b. Time invariance of transient land-ocean surface temperature contrast}

During transient climate change, LST and SST anomalies relax strongly toward the value of $\phi$ seen at 
equilibrium (LC07; JGW08), even though the effective heat capacity of the ocean is much larger than that of the land. LC07 suggested that the processes governing relaxation cause heat transport anomaly between the land and ocean surfaces. For example, if a GCM is perturbed by applying a globally uniform radiative forcing, we might expect LSTs to move to the new equilibrium much more rapidly than SSTs. We know that this does not happen, however, as LST and SST anomalies stay quite close to a constant ratio: there is only a small rapid adjustment in LST. If we assume for now that land and ocean temperatures are merely a function of heat stored (this may not be the case for a fully dynamical ocean), then the flux into the land due to radiative forcing must be reduced to a level that keeps the rate of land warming in step with ocean warming with only a small rapid change in LST. Hence, given that the atmosphere does not store significant heat on climatological time scales (although see the appendix), the imposed TOA radiative forcing over land must either result in net heat flow from the atmosphere over land to the atmosphere over ocean or the forcing must be opposed by an upward radiative flux at the TOA over land. LC07 favored the first possibility and therefore expected a change in heat transport that slows land warming and accelerates ocean warming until equilibrium is reached. We call this the "heat transport" hypothesis. The second possibility implies that the small rapid LST change and accompanying changes in atmospheric conditions are sufficient to cause a balancing upward radiative flux at the TOA over land. This may be possible, for example, given that the bulk of atmospheric water vapor climate change anomalies are evaporated from the ocean surface. In the absence of significant water vapor feedback, a limited LST change might produce an increase in outgoing longwave radiation sufficient to balance radiative forcing. Subsequent land warming that is in step with ocean warming would then be driven by changes in atmospheric conditions because of changes in SST that are not associated with an ocean-land heat transport. We call this the "nonenergetic teleconnection" hypothesis.

In an alternative experiment, the GCM is forced by imposing an SST anomaly; we find that LSTs increase, producing similar $\phi$ to the radiatively forced case. Under the heat transport hypothesis, we expect anomalous heat to flow from the ocean to the land surface, warming the land. Under the nonenergetic teleconnection hypothesis, we expect a downward heat flux at the land surface because of changes in atmospheric conditions driven by the ocean but do not expect anomalous heat to flow from the ocean to the land surface.

The heat transport hypothesis fits in with the ideas of Forster et al. (2000), Boer and Yu (2003), and Joshi et al. (2003), as forcings or surface temperature perturbations are roughly equally important wherever these are applied. Meanwhile, the nonenergetic teleconnection hypothesis suggests that radiative forcing or LST perturbations are relatively unimportant, as argued by CS09 and D09 (the hypothesis was not made by CS09 or by D09, but it would be strong support for their work if true).

Note that a third possibility for the relative time invariance of $\phi$ under radiative forcing is that SST change is a function of the rapidity at which forcing is applied. If rapid spikes in forcing do not penetrate far into the ocean, then the ocean may show a smaller heat capacity than expected and be capable of more rapid surface temperature change. For the most part, the model experiments in this study do not feature dynamical ocean models and cannot show variable ocean heat capacity. We, therefore, do not investigate this possibility. Hence, if this effect is dominant in the real ocean, then our results will not be relevant for understanding observed $\phi$ during rapid changes in forcing.

Using a two-box energy balance model (EBM), LC07 calculated the land-to-ocean heat flow anomaly with respect to control conditions that would be expected under the heat transport hypothesis. It will be instructive to compare their predictions with our idealized model simulations. Hence, we derive their equations in section $2 \mathrm{~b}(1)$ and adapt them for use with our idealized GCM experiments in section $2 b(2)$.

\section{1) HEAT TRANSPORT HYPOTHESIS}

LC07's two-box EBM describes small changes in climate variables, denoted by $\Delta$, that occur in response to radiative forcing or imposed changes in surface temperatures. Terms subscribed with $G$ are global mean quantities, terms subscribed with $L$ are land means, and terms subscribed with $O$ are ocean means. Figure 1a is a schematic diagram of the EBM. Mean ocean surface temperature change, $\Delta T_{O}(\mathrm{~K})$, is given by

$$
\Delta Q_{G}-\frac{\Delta T_{O}}{\lambda_{O}}+\frac{\Delta A}{1-f}=\Delta U_{O},
$$

where $\Delta Q_{G}\left(\mathrm{~W} \mathrm{~m}^{-2}\right)$ is the radiative forcing due to external factors, $\lambda_{O}\left(\mathrm{KW}^{-1} \mathrm{~m}^{2}\right)$ is the ocean-only climate sensitivity parameter, $f$ is the land fraction, $\Delta A\left(\mathrm{Wm}^{-2}\right)$ is the land-to-ocean heat flow anomaly, and $U_{O}\left(\mathrm{~W} \mathrm{~m}^{-2}\right)$ is the ocean heat uptake anomaly. Mean land temperature change, $\Delta T_{L}(\mathrm{~K})$, is given by

$$
\Delta Q_{G}-\frac{\Delta T_{L}}{\lambda_{L}}-\frac{\Delta A}{f}=\Delta U_{L},
$$

where $\lambda_{L}\left(\mathrm{KW}^{-1} \mathrm{~m}^{2}\right)$ is the land climate sensitivity parameter and $\Delta U_{L}\left(\mathrm{~W} \mathrm{~m}^{-2}\right)$ is the land heat uptake 
(a) Two-box EBM

(b) Slab model initial
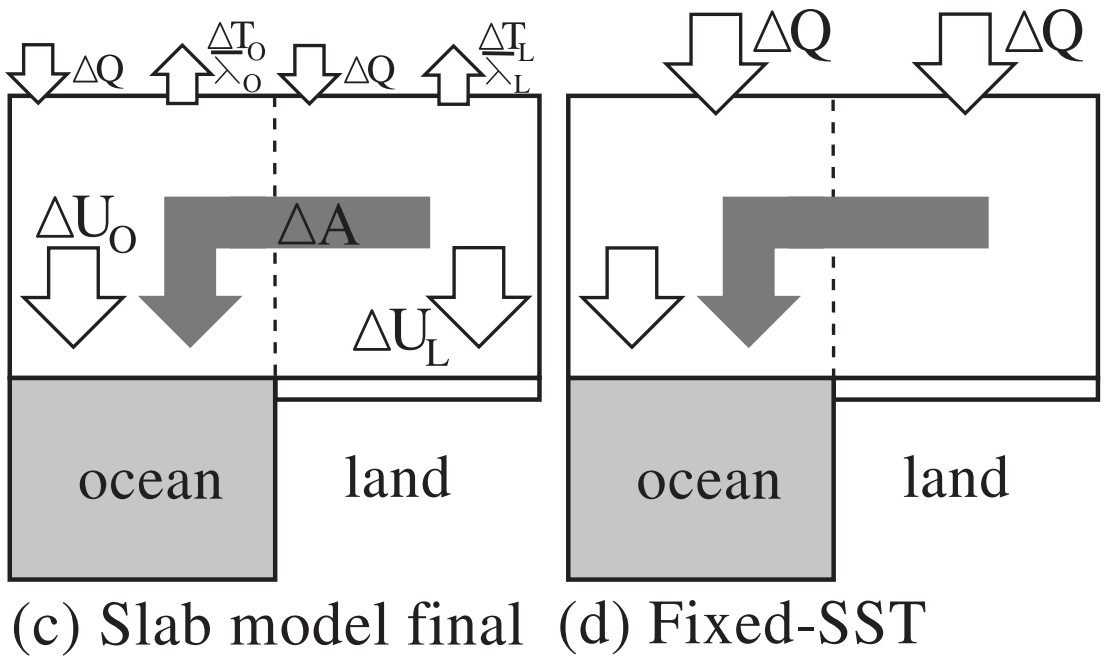

(d) Fixed-SST
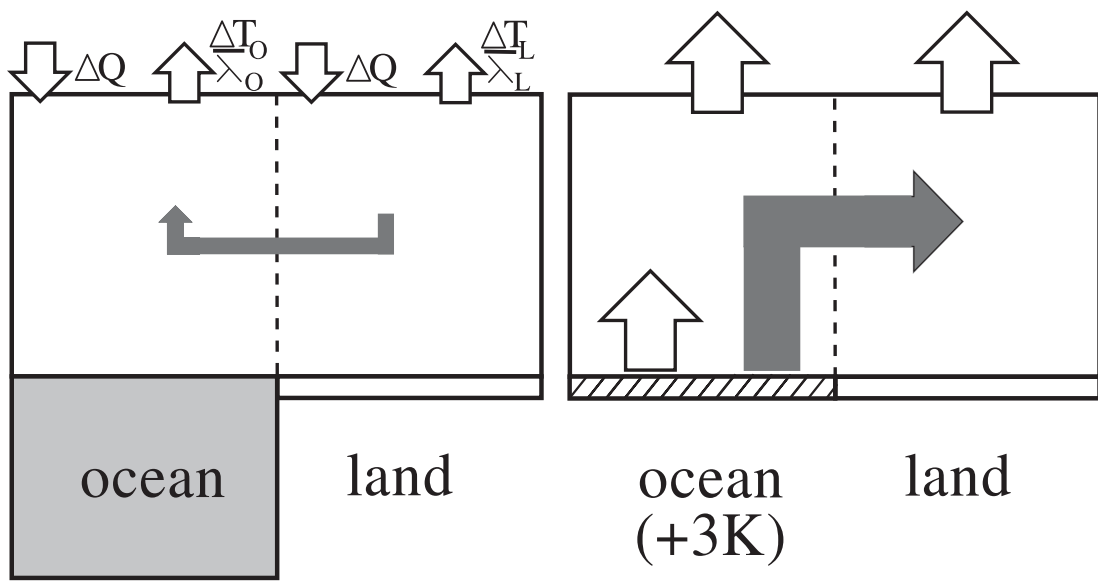

FIG. 1. Schematic diagram of energy flow under the heat transport hypothesis. (a) Terms in Eqs. (1) and (2). (b) The initial state in a slab model after the application of a globally uniform forcing, $\Delta Q_{G}$ (white arrows). (Strictly after rapid surface and atmospheric adjustments have taken place but before significant $\Delta T_{G}$.) The $\Delta Q_{G}$ over land is transferred to the ocean by $\Delta A$ (gray arrow). Hence, the ocean absorbs both land and ocean $\Delta Q_{G}$ (white arrows), and $\Delta T_{L}$ and $\Delta T_{O}$ increase such that $\phi$ remains constant. (c) As equilibrium is approached, the net energy fluxes across the land and ocean surfaces tend to zero, and the net flux anomalies at the land and ocean TOA tend to small values, causing $\Delta A$ to tend to a small TOA land to TOA ocean transport of either sign. We parameterize this as $\alpha \Delta T_{O}=\alpha_{G} \Delta T_{G}$. (d) The steady state of a perturbed SST experiment. The ocean causes land warming and globally uniform TOA response fluxes (white arrows) via $\Delta A$ (gray arrow).

anomaly. The EBM is similar to those models used previously to describe land and ocean temperature changes, such as those of Murphy (1995) and Huntingford and Cox (2000). The important difference is that the land-to-ocean heat transport term $\Delta A$ is not defined.

For simplicity, the EBM assumes that $\Delta Q_{G}$ is globally uniform, as it nearly is for well-mixed greenhouse gases (Forster et al. 2007). Land and ocean TOA flux anomalies only depend on $\Delta Q_{G}$ and the surface temperature anomaly in each box (Fig. 1a). Hence, to relax $\phi=\Delta T_{L} /$ $\Delta T_{O}$ toward its equilibrium value during transient climate change requires the land and ocean surfaces to exchange heat.

Subtracting Eq. (2) from (1) reveals the land-toocean heat transport necessary to preserve time invariant $\phi$ :

$$
\Delta A=f(1-f)\left(\Delta U_{O}-\Delta U_{L}+\alpha \Delta T_{O}\right),
$$


where $-\alpha=\left(\phi / \lambda_{L}\right)-\left(1 / \lambda_{O}\right)$ is a constant, as $\phi$ is constant. The $\Delta U_{O}$ and $\Delta U_{L}$ terms are substantial for transient climate change but small for equilibrium climate change because long-term mean land and ocean heat uptake are zero at equilibrium. Conversely, the $\alpha \Delta T_{O}$ term only depends on the amount of ocean warming: it does not matter whether the perturbed climate is in equilibrium. Given that surface fluxes are small at equilibrium, $\alpha \Delta T_{O}$ must be principally balanced by TOA flux anomalies. Hence, $\lambda_{O}, \lambda_{L}$, and $\alpha$ can be thought of as representing mechanisms (i)-(iii) from section $2 \mathrm{a}$, while the $\Delta U_{O}-$ $\Delta U_{L}$ part of $\Delta A$ maintains equilibrium-like $\phi$ away from equilibrium.

\section{2) Application to ideAlized GCM EXPERIMENTS}

The idealized GCM experiments that we will consider feature either an ocean model and are perturbed by applying a radiative forcing or they are prescribed SST experiments that have no ocean at all and are perturbed by changing SSTs (see section 3). Importantly, the perturbed SST experiments gain or lose heat at the ocean surface without changes in $\Delta T_{O}$. In both types of experiment $\Delta U_{L} \sim 0$ and global mean net downward TOA radiative flux $\Delta N_{G}\left(\mathrm{~W} \mathrm{~m}^{-2}\right)$ is absorbed by the ocean alone (e.g., Andrews et al. 2009) [note that observations indicate that the real land surface is capable of significant heat uptake (Beltrami et al. 2002; Smerdon and Stieglitz 2006; Stevens et al. 2007)]. Hence, $\Delta U_{O} \simeq \Delta N_{G} /(1-f)$, and Eq. (3) becomes

$$
\Delta A \simeq f\left[\Delta N_{G}+(1-f) \alpha_{G} \Delta T_{G}\right],
$$

where we have written $\alpha_{G} \Delta T_{G}=\alpha \Delta T_{O}, \Delta T_{G}$ is global mean surface temperature change $(\mathrm{K})$ and $\alpha_{G}=\alpha /[1-$ $f(1-\phi)]$ is a constant. This allows for a cleaner separation of the equation into $\Delta T_{G}$-dependent and -independent parts $\left(\Delta T_{O} / \Delta T_{G}\right.$ is time invariant, where $\phi$ is time invariant).

The global mean energy balance anomaly at TOA can be expressed as

$$
\Delta N_{G}=\Delta Q_{G}-\frac{\Delta T_{G}}{\lambda_{G}},
$$

where $\lambda_{G}$ is the global climate sensitivity parameter $\left(\mathrm{KW}^{-1} \mathrm{~m}^{2}\right)$ (e.g., Gregory et al. 2004; Hansen et al. 2005). In a GCM experiment perturbed by a radiative forcing, initial $\Delta N_{G} \sim \Delta Q_{G}$ (Fig. 1b). As the climate warms, $\Delta N_{G}$ decreases with increasing $\Delta T_{G}$ until $\Delta N_{G} \sim 0$ at equilibrium (Fig. 1c). Hence, if the heat transport hypothesis is correct, initial $\Delta A \sim f \Delta Q_{G}$ before tending to $\Delta A \sim$ $f(1-f) \alpha_{G} \Delta T_{G}$ at the new equilibrium, from Eq. (4). In a
GCM experiment perturbed by increasing $\Delta T_{O}, \Delta Q_{G}=0$. Under the heat transport hypothesis, we expect $\Delta A \sim$ $-\Delta T_{G} / \lambda_{G}$ (Fig. 1d). Under the nonenergetic teleconnection hypothesis, we cannot predict $\Delta A$. However, we know that if $\Delta A$ is nonzero, then it must be balanced by TOA heat fluxes rather than surface fluxes, as the land-toocean surface heat transport is predicted to be zero.

\section{GCM data}

To test the hypotheses, we take data from a variety of "slab," perturbed SST, and two fully coupled GCM experiments. Slab models couple the atmosphere to a shallow (typically $50 \mathrm{~m}$ deep) thermodynamic mixed layer ocean. Computational cost is much reduced compared with experiments where the atmosphere is coupled to a full dynamical ocean, as the GCM obtains a new equilibrium after perturbation in a few decades. Heat "flux corrections" are applied at the ocean surface to partially compensate for missing ocean heat transports that exist in the real ocean. Sea ice is interactive, as with a full GCM. (However, in the perturbed experiments, ocean temperatures under the sea ice are not perturbed and hence sea ice coverage changes little). The prescribed SST experiments omit the numerical ocean simulation. Instead, SSTs are maintained at "control" present-day levels or present-day levels plus a globally uniform perturbation. The ocean surface is able to absorb or emit any amount of heat without suffering a change in temperature, meaning that the long-term mean of ocean heat uptake $\Delta U_{O}$ is not necessarily zero in steady state. The fully coupled experiments couple the atmosphere to a full ocean model that simulates dynamics and heat transports.

We take slab data from the Quantifying Uncertainty in Model Predictions (QUMP) project (Murphy et al. 2004; Webb et al. 2006) for 188 models based on the Hadley Centre Slab Model, version 3 (HadSM3) (Pope et al. 2000; Williams et al. 2001a,b), but physically perturbed in their subgrid-scale parameterization to explore aspects of modeling uncertainty. We also take data from the Cloud Feedback Model Intercomparison Project (CFMIP) (see acknowledgments) for the Canadian Centre for Climate Modelling and Analysis Coupled General Circulation Model, version 3.1 (CCCma CGCM 3.1); ECHAM5; Geophysical Fluid Dynamics Laboratory (GFDL); Hadley Centre Global Slab Model, version 1 (HadGSM1); Hadley Centre Slab Model, version 4 (HadSM4); Model for Interdisciplinary Research on Climate 3.2, low-resolution version (MIROC-lores, hereafter MIROC); and University of Illinois at Urbana-Champaign (UIUC) slab models. Finally, we have an ensemble of National Center for Atmospheric Research Community Atmosphere Model, version 3 (NCAR CAM3), slab runs prepared at NCAR (Collins 
et al. 2006 and see acknowledgments). Equilibrium unperturbed control experiments and experiments in which the concentration of atmospheric $\mathrm{CO}_{2}$ is doubled $(2 \times$ $\mathrm{CO}_{2}$ ) are available in each case. "Spinup" data, in which the model makes the transition from the control state to its new equilibrium after perturbation, are available for the QUMP models, CCCma, GFDL, and CAM3. We have four spinups for CAM3, and one for each of the other models. The spinups allow for the separation of rapid land surface and atmospheric adjustments from feedbacks that scale approximately the with global mean surface temperature change (Gregory et al. 2004). In the QUMP, HadSM3, HadSM4, and HadGSM1 models, control SSTs are relaxed toward a 1951-80 climatology from the Global Sea Ice and Sea Surface Temperature dataset (GISST) (Rayner et al. 1996). The SSTs in CAM3 and CFMIP are similar, although those in CCSM3 appear to correspond to preindustrial conditions (control SST periods were neither specified nor reported back for CFMIP).

We take prescribed SST experiments from six QUMP models, the Hadley Centre Atmospheric Model, version 3 (HadAM3, the atmospheric component of HadSM3), the Hadley Centre Global Atmospheric Model, version 2 (HadGAM2) (Martin et al. 2006), and CAM3. Unperturbed control experiments are available for each model. Globally uniform SST perturbation experiments are available for HadAM3 (+3 K) and HadGAM2 (+4 K). In HadAM3, sea ice is interactive and relaxed back to control conditions as with the slab experiments; in HadGAM2, sea ice is prescribed at control conditions throughout. Hansen experiments (Hansen et al. 2002), in which SSTs and sea ice are held at control values but the atmospheric $\mathrm{CO}_{2}$ concentration is doubled, are available for QUMP, HadAM3, and CAM3. The Hansen experiments show only the global mean surface temperature's independent rapid adjustments. We have one more HadAM3 experiment that includes a uniform $+3 \mathrm{~K} \mathrm{SST}$ perturbation and a doubling of $\mathrm{CO}_{2}$ concentration, allowing us to investigate whether the separate perturbations add linearly. The $+3 \mathrm{~K}$ SST perturbation is very close to that which would result from the $2 \times \mathrm{CO}_{2}$ forcing, so that this experiment is near equilibrium. (In an experiment in which the ocean is free to respond to forcing, such as the slab experiments described above, the SST response to forcing is not spatially uniform.) Control SSTs in HadAM3 and HadGAM2 are specified from GISST; those in CAM3 are quite similar.

We take fully coupled data from the third climate configuration of the Met Office Unified Model (HadCM3) (Gordon et al. 2000). One equilibrium unperturbed control experiment and one $2 \times \mathrm{CO}_{2}$ experiment are available. The perturbed experiment starts from the control state and is run for $20 \mathrm{yr}$. Information for all the GCMs is summarized in Table 1.
TABLE 1. Number of perturbed ensemble members, number of years for each ensemble member, and values of $\phi_{\text {trans }}$ and $\phi_{\text {eqm }}$ in the slab, fully coupled, and perturbed SST experiments. Values of $\phi_{\text {trans }}$ are not listed for slab models with no spinup data. Errors are $5 \%-95 \%$ confidence intervals.

\begin{tabular}{|c|c|c|c|c|c|}
\hline Model & $\begin{array}{c}\text { No. of } \\
\text { runs }\end{array}$ & $\begin{array}{c}\text { No. of } \\
\text { years }\end{array}$ & $\phi_{\text {trans }}$ & $\phi_{\text {eqm }}$ & $\Delta U_{\mathrm{GA}} / \Delta N_{G}$ \\
\hline \multicolumn{6}{|l|}{ Slab } \\
\hline QUMP & 188 & $\geq 24$ & $1.38 \pm 0.31$ & $1.55 \pm 0.23$ & $0.07 \pm 0.09$ \\
\hline CAM3 & 4 & $\geq 14$ & $1.12 \pm 0.15$ & $1.34 \pm 0.11$ & $0.06 \pm 0.05$ \\
\hline $\mathrm{CCCma}$ & 1 & 40 & $1.40 \pm 0.16$ & $1.39 \pm 0.06$ & $0.04 \pm 0.11$ \\
\hline ECHAM5 & 1 & 20 & - & $1.57 \pm 0.07$ & - \\
\hline GFDL & 1 & 100 & $1.30 \pm 0.14$ & $1.38 \pm 0.10$ & $0.17 \pm 0.10$ \\
\hline HadGSM1 & 1 & 12 & - & $1.38 \pm 0.07$ & - \\
\hline HadSM4 & 1 & 19 & - & $1.59 \pm 0.08$ & - \\
\hline MIROC & 1 & 20 & - & $1.35 \pm 0.08$ & - \\
\hline UIUC & 1 & 20 & - & $1.24 \pm 0.07$ & - \\
\hline \multicolumn{6}{|c|}{ Fully coupled } \\
\hline HadCM3 & 1 & 20 & $1.52 \pm 0.20$ & - & $0.09 \pm 0.09$ \\
\hline \multicolumn{6}{|c|}{ Prescribed SST } \\
\hline HadGAM2 & 1 & 5 & - & $1.41 \pm 0.12$ & $-0.04 \pm 0.02$ \\
\hline HadAM3 & 1 & 20 & - & $1.29 \pm 0.06$ & $-0.04 \pm 0.07$ \\
\hline \multicolumn{6}{|l|}{ Hansen } \\
\hline QUMP & 6 & $\geq 10$ & - & - & $0.00 \pm 0.02$ \\
\hline CAM3 & 1 & 15 & - & - & $0.01 \pm 0.23$ \\
\hline HadAM3 & 1 & 20 & - & - & $0.01 \pm 0.06$ \\
\hline \multicolumn{6}{|c|}{ Prescribed SST $+2 \times \mathrm{CO}_{2}$} \\
\hline HadAM3 & 1 & 19 & - & $1.52 \pm 0.06$ & $-0.32 \pm 0.46$ \\
\hline
\end{tabular}

\section{Results}

\section{a. Land-ocean surface temperature contrast}

We begin by confirming that changes in surface temperature with respect to control conditions in our $\mathrm{CO}_{2}$ and SST-forced runs are as described by JGW08 and CS09. We calculate $\phi$ during the spinup and steady-state phases of our runs (Table 1). The subscript trans indicates values calculated from the first $10 \mathrm{yr}$ for the slab spinups and the full $20 \mathrm{yr}$ for fully coupled HadCM3; the subscript eqm indicates values calculated from the stable equilibrium last $10 \mathrm{yr}\left(2 \times \mathrm{CO}_{2}\right)$ control states for the slab runs. All values are greater than one, as expected. Error bars for values of $\phi_{\text {trans }}$ and $\phi_{\text {eqm }}$ overlap apart from in CAM3, although they are not formally consistent, as a Welch's $t$ test shows the mean values to be significantly different in all cases barring CCCma [Welch's $t$ test is the appropriate test where sample variances are not expected to be the same (Welch 1947)]. Central estimates of $\phi_{\text {trans }}$ are less than $\phi_{\text {eqm }}$ apart from in CCCma. This is possibly because $\phi_{\text {trans }}$ is underestimated by ordinary least squares regression because of noise in $\Delta T_{O}$, or possibly because $\Delta T_{L}$ increases slightly at the beginning of a perturbed run before relaxing toward $\phi_{\text {eqm }}$ as equilibrium is approached (JGW08). Values from the perturbed SST runs calculated from averaging across all but the first year of the runs are 
(a) QUMP, CCCma, HadCM3 and HadAM3

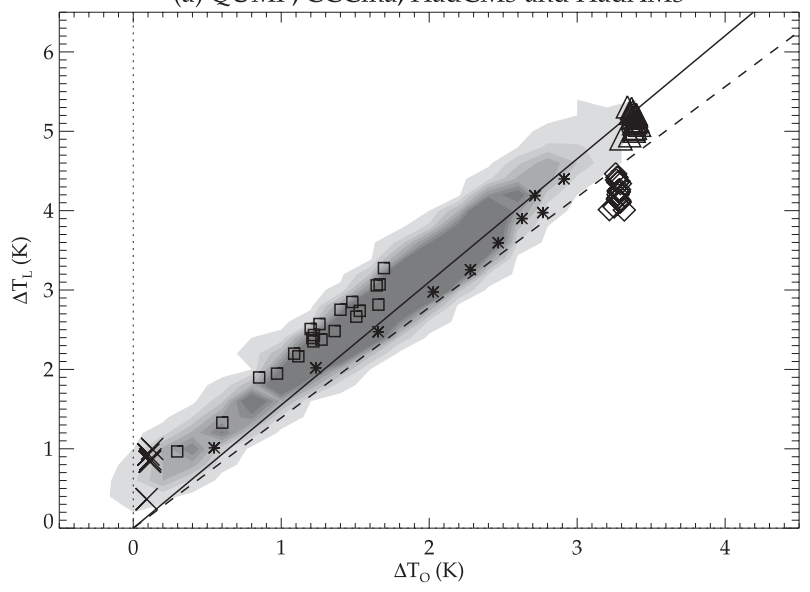

(b) CAM3, GFDL and HadGAM2

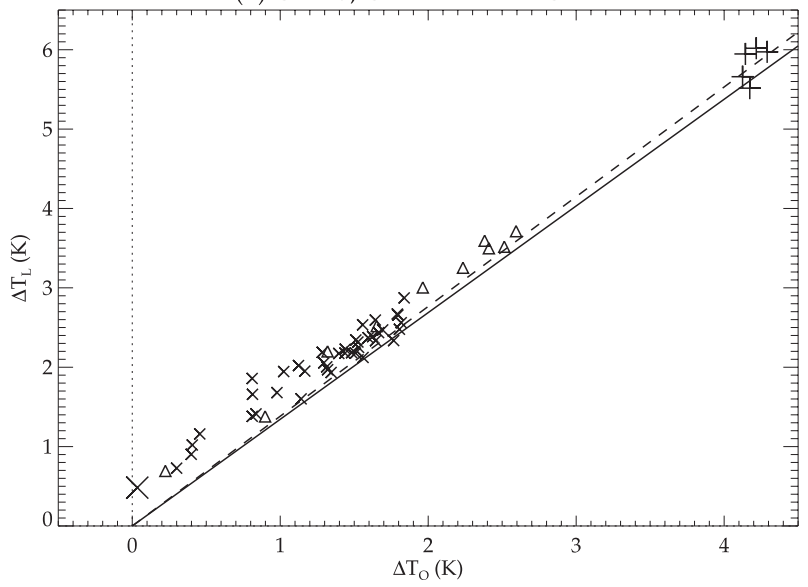

FIG. 2. Annual mean $\Delta T_{L}$ plotted against $\Delta T_{O}$ for the slab, HadCM3, and prescribed SST runs and Hansen time mean values (first $10 \mathrm{yr}$ only for slab models). Two panels are used for clarity. (a) QUMP is represented by gray shading; darker shading indicates a higher density of points. The stars represent CCCma, the squares HadCM3, the large diamonds $+3 \mathrm{~K}$ SST HadAM3, the large triangles $+3 \mathrm{~K} \mathrm{SST}+\left(2 \times \mathrm{CO}_{2}\right)$ HadAM3, and the large diagonal crosses QUMP Hansen experiments. The solid line represents $\Delta T_{L}$ predicted from $\phi_{\mathrm{eqm}} \Delta T_{O}$ for QUMP and the dashed line for CCCma. (b) The small diagonal crosses represent CAM3, the large diagonal cross the CAM3 Hansen experiment, the triangles GFDL, and the large vertical crosses $+4 \mathrm{~K}$ SST HadGAM2. The solid line represents $\Delta T_{L}$ predicted from $\phi_{\text {eqm }} \Delta T_{O}$ for CAM3 and the dashed line for GFDL.

similar to slab model values, in agreement with CS09 and D09.

Figure 2 is a plot of slab, fully coupled, prescribed SST, and Hansen $\Delta T_{L}$ against $\Delta T_{O}$. The plots confirm that annual mean $\Delta T_{L}$ and $\Delta T_{O}$ stay quite close to a constant ratio in the slab and prescribed SST runs and that $\Delta T_{L}$ increases slightly at the beginning of the slab and fully coupled and Hansen runs. Hence, where $\Delta N_{G}$ is positive, at the beginning of the slab and fully coupled spinups and in the Hansen runs, $\Delta T_{L}$ tends to increase slightly more than necessary to yield equilibrium $\phi$. Where $\Delta N_{G}$ is negative, in the HadAM3 +3K SST experiment without increased $\mathrm{CO}_{2}, \Delta T_{L}$ does not increase as much as in the $+3 \mathrm{~K}+\left(2 \times \mathrm{CO}_{2}\right)$ experiment, where $\Delta N_{G}$ is much closer to zero. These findings are consistent with JGW08 and CS09.

\section{b. Land-to-ocean heat transport}

Atmospheric heat storage is fairly insignificant compared with TOA and surface heat fluxes on annual mean time scales. Hence, we can estimate annual mean landto-ocean heat transport in our models by summing radiative, latent, and sensible heat fluxes at the TOA and surface over either the land or the ocean. In our slab GCM experiments, total unperturbed control land-to-ocean transport, $A$, is around $-5 \mathrm{~W} \mathrm{~m}^{-2}$ or $-2 \mathrm{PW}$, which compares reasonably with estimates from recent observations of about -2 to -3 PW from Fasullo and Trenberth (2008a).

We now compute land-to-ocean heat transport anomalies for the perturbed runs with respect to control conditions, $\Delta A$ (see the appendix for details of the calculation, including how we remove an estimate of the effect of atmospheric energy absorption and model energy nonconservation errors). To compare these to heat transport hypothesis predictions, we also calculate anomalies for the components of Eq. (4). The term $\Delta N$ is calculated by taking net downward TOA radiative flux anomalies with respect to control conditions in the perturbed runs. The term $\alpha_{G}$ is calculated from $\Delta A$ and $\Delta T_{G}$ anomalies taken at the new equilibrium in the perturbed slab experiments [at the new equilibrium, $\Delta N_{G} \sim 0$, meaning that $\Delta A \sim$ $f(1-f) \alpha_{G} \Delta T_{G}$ from Eq. (4)]. We separate our results into a $\Delta T_{G}$-independent forcing component and a $\Delta T_{G}$ dependent component using the methods described below. The Hansen runs have only a $\Delta T_{G}$ independent component; the perturbed SST runs without $2 \times \mathrm{CO}_{2}$ have only a $\Delta T_{G}$ dependent component; and the slab, fully coupled, and perturbed SST runs with $2 \times \mathrm{CO}_{2}$ runs have both.

For the slab experiments, we regress annual mean $\Delta A$ and $\Delta N_{G}$ against $\Delta T_{G}$ for the first $10 \mathrm{yr}$ of each run. We write $\Delta A \simeq \beta_{\Delta A} \Delta T_{G}+\Delta A_{\Delta T_{G}=0}$ and $f \Delta N_{G} \simeq \beta_{f \Delta N_{G}} \Delta T_{G}+$ $f \Delta N_{G, \Delta T_{G}=0}$, where the $\beta$ s are gradients against $\Delta T_{G}$ ( $\Delta T_{G}$ dependent) and $\Delta A_{\Delta T_{G}=0}$ and $\Delta N_{G, \Delta T_{G}=0}$ are the $y$ intercepts $\left(\Delta T_{G}\right.$ independent) (Gregory et al. 2004).

For the Hansen and perturbed SST experiments, we calculate $\Delta A, \Delta N_{G}$, and $\Delta T_{G}$ from the mean difference between the perturbed and control values, using all data apart from the first year of each run. For the perturbed SST experiments, we calculate the dependency of $\Delta A$ and $\Delta N_{G}$ on temperature by dividing by $\Delta T_{G}$. The Hansen experiments allow us to analyze $\Delta A$ and $\Delta N_{G}$ near $\Delta T_{G}=$ 0 ; the perturbed SST experiments allow us to analyze $\Delta A$ 
TABLE 2. Values of $\Delta A, f \Delta N$, and $\Delta A_{\mathrm{TOA}}$ at $\Delta T_{G}=0\left(\mathrm{~W} \mathrm{~m}^{-2}\right)$ and dependence on $\Delta T_{G}, \beta \mathrm{s}\left(\mathrm{W} \mathrm{m}^{-2} \mathrm{~K}^{-1}\right)$ and $f(1-f) \alpha_{G}\left(\mathrm{~W} \mathrm{~m}{ }^{-2} \mathrm{~K}^{-1}\right)$. Slab and fully coupled model $\Delta T_{G}=0$ and $\beta$ values are calculated from regression. Perturbed SST and Hansen values are calculated by averaging across the stable section of the runs. Errors are 5\%-95\% confidence intervals. QUMP errors are based on the range of estimates across ensemble members; others are based on residual variance. The $\Delta A$ at $\Delta T_{G}=0$ (column 2) can be compared to the prediction (column 4), and the change in $\Delta A$ per degree warming (column 3) can be compared to the prediction (columns $5+6$ ).

\begin{tabular}{|c|c|c|c|c|c|c|c|}
\hline \multirow[b]{2}{*}{ Model } & \multicolumn{2}{|c|}{$\Delta A$} & \multicolumn{2}{|c|}{$f \Delta N$} & \multirow[b]{2}{*}{$f(1-f) \alpha_{G}$} & \multicolumn{2}{|c|}{$\Delta A_{\mathrm{TOA}}$} \\
\hline & $\Delta A_{\Delta T_{G}=0}$ & $\beta_{\Delta A}$ & $f \Delta N_{G, \Delta T_{G}}=0$ & $\beta_{f} \Delta_{N}$ & & $\Delta A_{\mathrm{TOA}, \Delta T_{G}}=0$ & $\beta_{\triangle A_{\mathrm{TOA}}}$ \\
\hline \multicolumn{8}{|l|}{ Slab } \\
\hline QUMP & $0.98 \pm 0.60$ & $-0.33 \pm 0.21$ & $1.03 \pm 0.49$ & $-0.35 \pm 0.28$ & $0.00 \pm 0.04$ & $0.05 \pm 0.53$ & $-0.02 \pm 0.19$ \\
\hline CAM3 & $0.90 \pm 0.18$ & $-0.35 \pm 0.12$ & $1.06 \pm 0.17$ & $-0.50 \pm 0.10$ & $0.00 \pm 0.00$ & $-0.03 \pm 0.16$ & $0.08 \pm 0.10$ \\
\hline CCCma & $1.13 \pm 0.20$ & $-0.37 \pm 0.08$ & $1.30 \pm 0.30$ & $-0.33 \pm 0.12$ & $-0.01 \pm 0.01$ & $-0.05 \pm 0.31$ & $-0.07 \pm 0.12$ \\
\hline ECHAM5 & - & - & - & - & $-0.09 \pm 0.04$ & - & - \\
\hline GFDL & $0.83 \pm 0.44$ & $-0.39 \pm 0.19$ & $1.31 \pm 0.37$ & $-0.41 \pm 0.16$ & $-0.03 \pm 0.02$ & $-0.16 \pm 0.37$ & $-0.01 \pm 0.16$ \\
\hline HadSM4 & - & - & - & - & $-0.07 \pm 0.04$ & - & - \\
\hline MIROC & - & - & - & - & $-0.01 \pm 0.01$ & - & - \\
\hline \multicolumn{8}{|l|}{ Fully coupled } \\
\hline HadCM3 & $1.41 \pm 0.26$ & $-0.38 \pm 0.16$ & $1.24 \pm 0.32$ & $-0.44 \pm 0.20$ & - & $0.31 \pm 0.28$ & $0.00 \pm 0.17$ \\
\hline \multicolumn{8}{|c|}{ Prescribed SST } \\
\hline HadGAM2 & - & $-0.41 \pm 0.11$ & - & $-0.45 \pm 0.15$ & - & - & $0.04 \pm 0.06$ \\
\hline HadAM3 & - & $-0.36 \pm 0.09$ & - & $-0.36 \pm 0.05$ & - & - & $-0.01 \pm 0.01$ \\
\hline \multicolumn{8}{|l|}{ Hansen } \\
\hline QUMP & $1.33 \pm 0.80$ & - & $1.07 \pm 0.30$ & - & - & $0.27 \pm 0.54$ & - \\
\hline CAM3 & $1.00 \pm 0.29$ & - & $1.12 \pm 0.15$ & - & - & $0.09 \pm 0.20$ & - \\
\hline HadAM3 & $1.36 \pm 0.19$ & - & $1.08 \pm 0.14$ & - & - & $0.28 \pm 0.22$ & - \\
\hline \multicolumn{8}{|c|}{ Prescribed SST $+\left(2 \times \mathrm{CO}_{2}\right)$} \\
\hline HadAM3 & - & $0.03 \pm 0.02$ & - & $-0.04 \pm 0.02$ & - & - & $0.07 \pm 0.03$ \\
\hline
\end{tabular}

and $\Delta N_{G}$ where SST changes are prescribed directly rather than being a response to forcing.

Values of the $\Delta T_{G}$ independent and dependent components of $\Delta A$ and Eq. (4) are given in Table 2. Annual mean values of $\Delta A$ are compared to regression estimates from Eq. (4) for the slab model and fully coupled HadCM3 experiments in Fig. 3. We see that there is a significant land-to-ocean heat transport anomaly immediately after $\mathrm{CO}_{2}$ forcing is applied as values of $\Delta A$ are substantial near $\Delta T_{G}=0$ (Table 2, column 2). The magnitude of $\Delta A$ then decreases as $\Delta T_{G}$ increases (Table 2, column 3) until $\Delta A$ reaches a small value at the new equilibrium (Fig. 3). Predictions from Eq. (4) are quite similar to $\Delta A$. At $\Delta T_{G}$ $=0$, predictions are typically slightly larger than $\Delta A$ (cf. Table 2, columns 2 and 4). Dependencies on $\Delta T_{G}$ are also similar (cf. Table 2, column 3 to Table 2, columns 5 and 6) (notice there is no estimate of $f(1-f) \alpha_{G}$ in column 6 for HadCM 3 because there is no perturbed equilibrium state from which to calculate $\Delta A$ ). Confidence intervals do overlap in all cases, but they are not formally consistent apart from in CCCma (Welch's $t$ test).

Results for the Hansen and perturbed SST experiments can be compared to the slab case. In the Hansen experiments, which approximate perturbed slab model conditions near $\Delta T_{G}=0, \Delta A$ flows from land to ocean and is similar to the prediction from Eq. (4) (cf. Table 2, columns 2 and 4 ). The perturbed SST experiments show a similar dependence of $\Delta A$ on $\Delta T_{G}$ as the slab runs, meaning that total $\Delta A$ flows from ocean to land in these experiments. There is no balancing contribution from radiative forcing as there is in the slab equilibria. Again, values predicted by Eq. (4) are similar (cf. Table 2, columns 3 and 5) and statistically consistent in the case of HadGAM2 (Welch's $t$ test) (notice there is no estimate of $f(1-f) \alpha_{G}$ in column 6 for the perturbed SST runs because there is no perturbed equilibrium state from which to calculate $\Delta A)$. The $+3 \mathrm{~K}+\left(2 \times \mathrm{CO}_{2}\right)$ HadAM3 experiment contains both forcing and $\Delta T_{G}$ dependent components. It shows small values of $\Delta A$ and $f \Delta N_{G}$, similar to the perturbed equilibrium states of the slab models.

Equation (4) assumes that the nonequilibrium part of $\Delta A$ is balanced by changes in surface fluxes (the equilibrium part, $f(1-f) \alpha_{G} \Delta T_{G}$, is balanced by TOA fluxes). There may also be a nonequilibrium component of $\Delta A$ that is balanced by changes in TOA fluxes, $\Delta A_{\mathrm{TOA}}$. The term $\Delta A_{\mathrm{TOA}}$ is the difference between the TOA flux anomaly over the land, $\Delta N_{L}$, and the TOA flux anomaly over the ocean, $\Delta N_{O}: \Delta A_{\mathrm{TOA}}=f(1-f)\left(\Delta N_{L}-\Delta N_{O}\right)$ (see the appendix). As above, we regress values of $\Delta A_{\mathrm{TOA}}$ against $\Delta T_{G}$ and write $\Delta A_{\mathrm{TOA}} \simeq \beta_{\Delta A_{\mathrm{TOA}}} \Delta T_{G}+\Delta A_{\mathrm{TOA}, \Delta T_{G}=0}$. Values of the $y$ intercept $\Delta A_{\mathrm{TOA}, \Delta T_{G}=0}$ and the gradient against $\Delta T_{G}, \beta_{\Delta A_{\text {TO }}}$, are given in Table 2, columns 7 and 8. In general, these are quite small compared with values of $\Delta A$, indicating that $\Delta A$ is primarily balanced by changes in surface fluxes. The exceptions are the significantly 


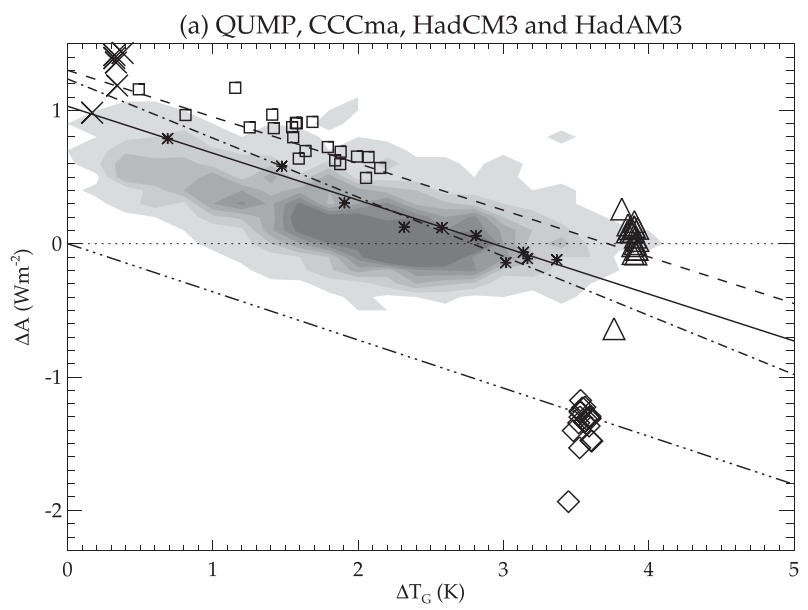

(b) CAM3, GFDL and HadGAM2

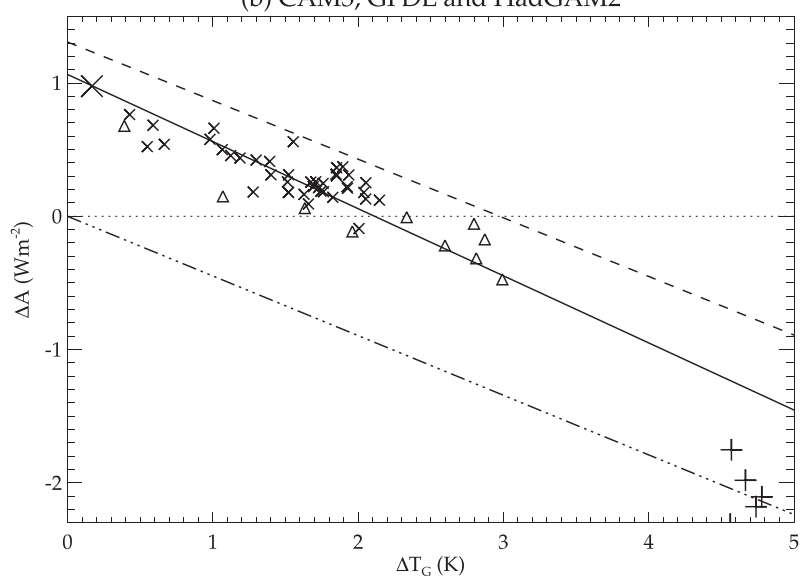

FIG. 3. Annual mean $\Delta A$, plotted against $\Delta T_{G}$ for the (perturbed control) slab, HadCM3 fully coupled and prescribed SST model runs, and Hansen mean values (first $10 \mathrm{yr}$ only for slab models). Lines of the fit $\left[\beta_{f \Delta N_{G}}+f(1-f) \alpha_{G}\right] \Delta T_{G}+f \Delta N_{\Delta T_{G}=0}$ are plotted for comparison (i.e., columns 4-6 of Table 2). Two panels are used for clarity. (a) QUMP $\Delta A$ is represented by gray shading; darker shading indicates a higher density of points. The stars represent CCCma, the squares HadCM3, the large diamonds $+3 \mathrm{~K}$ SST HadAM3, the large triangles $+3 \mathrm{~K} \mathrm{SST}+\left(2 \times \mathrm{CO}_{2}\right)$ HadAM 3 , and the large diagonal crosses QUMP Hansen experiments. For the prescribed SST experiments, the diamond and the triangle that are clearly below the clusters of diamonds and triangles represent the first year for the $+3 \mathrm{~K}$ and $+3 \mathrm{~K}+\left(2 \times \mathrm{CO}_{2}\right)$ experiments, respectively. The solid line represents $\left[\beta_{f \Delta N_{G}}+f(1-f) \alpha_{G}\right] \Delta T_{G}+f \Delta N_{G, \Delta T_{G}=0}$ for QUMP, the dashed line for CCCma, the dotted-dashed line for HadCM3, and the lower multidotted-dashed line for $+3 \mathrm{~K}$ SST HadAM3. (b) The small diagonal crosses represent CAM3 $\Delta A$, the triangles GFDL, the large vertical crosses represent $+4 \mathrm{~K}$ HadGAM2, and the large diagonal cross the CAM3 Hansen experiment. The solid line represents $\left[\beta_{f \Delta N_{G}}+f(1-f) \alpha_{G}\right] \Delta T_{G}+f \Delta N_{\Delta T_{G}=0}$ for CAM3, the dashed line for GFDL, and the lower multidotteddashed line for $+4 \mathrm{~K}$ HadGAM 2 .

nonzero values of $\Delta A_{\mathrm{TOA}, \Delta T_{G}=0}$ in the Hadley Centre models, the fully coupled HadCM3, and the HadAM3 and QUMP Hansen experiments. Given that $\Delta N_{O, L} \sim$ $\Delta Q_{O, L}$ at $\Delta T_{G}=0, \Delta A_{\mathrm{TOA}} \sim f(1-f)\left(\Delta Q_{L}-\Delta Q_{O}\right)$.
Hence, it appears that the effect of $\mathrm{CO}_{2}$ forcing at $\Delta T_{G}=$ 0 in these models is different over land and ocean and that our assumption that $\Delta Q_{G}$ is globally uniform is not justified here.

In summary, $\Delta A$ during slab and fully coupled spinup climate change is generally smaller than predicted by the heat transport hypothesis Eq. (4). However, we see from Fig. 3 that qualitative behavior is as expected. In the slab model experiments, $\Delta A$ is near $f \Delta Q_{G}$ at $\Delta T_{G}=0$. Hence, substituting into Eq. (2) we see that the majority of radiative forcing over land is balanced by $\Delta A$, meaning that $\Delta Q_{G}$ is being transported away from the land and absorbed by the ocean (Fig. 1b). The magnitude of $\Delta A$ then decreases approximately as $\Delta A \sim$ $f \Delta N_{G}$, reaching a small value at the new equilibrium (Fig. 1c). Meanwhile, perturbed SST experiments without increased $\mathrm{CO}_{2}$ - which are not in equilibrium, as $\Delta N_{G}$ is not close to zero-show large negative $\Delta A \sim$ $f \Delta N_{G}$ as heat flows from ocean to land, causing land warming, Fig. 1d. Finally, if a radiative forcing $\Delta Q_{G}$ is added to a perturbed SST experiment such that $\Delta N_{G} \sim 0$, then $\Delta A$ is found to be small, as for the perturbed equilibrium slab case. Under the nonenergetic teleconnection hypothesis, we would expect $\Delta A$ to be small or primarily balanced by TOA fluxes and therefore little able to affect surface temperatures. This is not the case in the models we investigate.

Clearly, there are substantial differences in the surface heat fluxes that balance $\Delta A$ between slab equilibria and prescribed SST experiments, even though surface temperature changes are similar. We do not have space to discuss individual fluxes here, but details of the relevant processes are given by Andrews et al. (2009) (slab), CS09, Dong et al. (2009) (prescribed SST), and Fasullo (2010) (fully coupled).

\section{c. Impact on precipitation, circulation, and cloud}

We now decompose the GCM precipitation, circulation, and cloud responses into $2 \times \mathrm{CO}_{2}$ forcing and $\Delta T_{G}$ dependent components to see if $\Delta A$ has consequences for the atmosphere. As above, we are particularly interested in the extent to which perturbed SST experiments replicate slab $2 \times \mathrm{CO}_{2}$ equilibria, because perturbed SST experiments show large ocean-to-land $\Delta A$, while slab equilibria show mostly $\Delta A \sim 0$. Slab spinups, meanwhile, show large land-to-ocean $\Delta A$. Related differences in surface fluxes could be associated with differences in circulation and other climate variables. We are also interested in the extent to which adding the $+3 \mathrm{~K}$ SST HadAM3 results to the $2 \times \mathrm{CO}_{2}$ Hansen HadAM3 results reproduces the $+3 \mathrm{~K} \mathrm{SST}+\left(2 \times \mathrm{CO}_{2}\right)$ results. This is potentially important for model intercomparison projects, such as CFMIP (see acknowledgments), that 
TABLE 3. Precipitation change at $\Delta T_{G}=0\left(\mathrm{~mm} \mathrm{day}^{-1}\right)$ and dependence on $\Delta T_{G}, \beta \mathrm{s}\left(\mathrm{mm} \mathrm{day}^{-1} \mathrm{~K}^{-1}\right)$. Slab and fully coupled model $\Delta T_{G}=0$ and $\beta$ values are calculated from regression. Perturbed SST and Hansen values are calculated by averaging across the stable section of the runs. Errors are 5\%-95\% confidence intervals. QUMP errors are based on the range of estimates across ensemble members; others are based on residual variance.

\begin{tabular}{|c|c|c|c|c|c|c|}
\hline \multirow[b]{2}{*}{ Model } & \multicolumn{3}{|c|}{$\Delta P_{\Delta T_{G}=0}$} & \multicolumn{3}{|c|}{$\beta \Delta P$} \\
\hline & Global & Land & Ocean & Global & Land & Ocean \\
\hline \multicolumn{7}{|l|}{ Slab } \\
\hline QUMP & $-0.06 \pm 0.04$ & $0.01 \pm 0.13$ & $-0.10 \pm 0.05$ & $0.07 \pm 0.02$ & $0.03 \pm 0.07$ & $0.09 \pm 0.03$ \\
\hline CAM3 & $-0.05 \pm 0.01$ & $0.05 \pm 0.04$ & $-0.08 \pm 0.01$ & $0.08 \pm 0.01$ & $0.07 \pm 0.03$ & $0.09 \pm 0.01$ \\
\hline CCCma & $-0.07 \pm 0.05$ & $0.02 \pm 0.23$ & $-0.11 \pm 0.05$ & $0.07 \pm 0.02$ & $0.03 \pm 0.09$ & $0.09 \pm 0.02$ \\
\hline GFDL & $-0.08 \pm 0.03$ & $-0.03 \pm 0.23$ & $-0.10 \pm 0.09$ & $0.06 \pm 0.01$ & $0.03 \pm 0.10$ & $0.08 \pm 0.04$ \\
\hline \multicolumn{7}{|c|}{ Fully coupled } \\
\hline \multicolumn{6}{|c|}{ Prescribed SST } & $0.10 \pm 0.01$ \\
\hline HadGAM & - & - & - & $0.08 \pm 0.02$ & $-0.00 \pm 0.00$ & $0.12 \pm 0.03$ \\
\hline HadAM3 & - & - & - & $0.09 \pm 0.00$ & $0.03 \pm 0.00$ & $0.11 \pm 0.01$ \\
\hline \multicolumn{7}{|l|}{ Hansen } \\
\hline QUMP & $-0.07 \pm 0.00$ & $0.05 \pm 0.01$ & $-0.12 \pm 0.00$ & - & - & - \\
\hline CAM3 & $-0.05 \pm 0.02$ & $0.05 \pm 0.07$ & $-0.10 \pm 0.03$ & - & - & - \\
\hline HadAM3 & $-0.07 \pm 0.01$ & $0.04 \pm 0.06$ & $-0.12 \pm 0.03$ & - & - & - \\
\hline \multicolumn{7}{|c|}{ Prescribed SST $+\left(2 \times \mathrm{CO}_{2}\right)$} \\
\hline HadAM3 & - & - & - & $0.06 \pm 0.00$ & $0.03 \pm 0.00$ & $0.07 \pm 0.00$ \\
\hline
\end{tabular}

depend on the ability of perturbed SST and Hansen experiments to separate climate responses to $\mathrm{CO}_{2}$ and $\Delta T_{G}$.

We expect regions of net export of $\Delta A$ to see anomalous convection and increases in precipitation, and regions of net import of $\Delta A$ to see anomalous subsidence and decreases in precipitation (in the tropics at least) (see section 2a). Hence, we expect increases in land precipitation and decreases in ocean precipitation in the Hansen experiments and in the slab models immediately following $\mathrm{CO}_{2}$ doubling, and increases in ocean precipitation and decreases in land precipitation in the perturbed SST experiments.

In the slab models and fully coupled HadCM3, changes in global mean precipitation are as expected from previous work. As in section $4 \mathrm{~b}$, we regress annual mean precipitation changes $\Delta P$ against $\Delta T_{G}$. We write $\Delta P \simeq \beta_{\Delta P} \Delta T_{G}+\Delta P_{\Delta T_{G}=0}$, where $\beta_{\Delta P}$ is the gradient against $\Delta T_{G}$ and $\Delta P_{\Delta T_{G}=0}$ is the $y$ intercept at $\Delta T_{G}=0$. We do this for global, land-only, and ocean-only spatial means. Initially $\left(\Delta T_{G} \sim 0\right)$, atmospheric longwave absorption increases as atmospheric opacity increases with increased $\mathrm{CO}_{2}$ concentration. Atmospheric latent heating and precipitation therefore decrease to maintain tropospheric energy balance, as the troposphere is unable to absorb significant heat because of its small heat capacity (Mitchell et al. 1987; Allen and Ingram 2002; Yang et al. 2003) (Table 3, column 2). Global mean precipitation then increases with global warming. Per degree warming, the global-temperature-dependent components are about the same as the global-temperature-independent components, meaning that global mean precipitation change is about 0 when $\Delta T_{G}=1 \mathrm{~K}$. Global mean precipitation then continues to increase until the initial decrease is outweighed by a factor of about $2-4$, depending on climate sensitivity (Table 3, column 5). We can also see the decrease in the Hansen experiments, where it is significant in QUMP.

Over land, changes are very uncertain, but there is a suggestion that mean precipitation increases initially (only significant in CAM3 for which we have four ensemble members) (Table 3, column 3). Ocean mean precipitation decreases significantly initially in the slab and Hansen experiments and more than the global mean. Both land and ocean mean precipitation tend to increase with $\Delta T_{G}$ in the slab models and HadCM3, although land changes are again very uncertain and only significant in CAM3 (Table 3, columns 6 and 7). The perturbed SST experiments show similar increases in global mean precipitation per degree warming as the slab experiments, although it appears that increases in ocean precipitation are slightly larger than in the slab experiments (Table 3, column 5). The $+3 \mathrm{~K}$ perturbed SST HadAM3 experiment shows significantly larger increases in ocean mean precipitation than the $+3 \mathrm{~K}+\left(2 \times \mathrm{CO}_{2}\right)$ experiment (Table 3 , column 7). Land mean precipitation change is almost the same in both experiments (Table 3, column 6).

Changes in equilibrium zonal-mean precipitation in the slab models show the classic pattern of hydrological intensification (e.g., Hulme et al. 1998), with large precipitation increases in the tropics, small increases or decreases in the subtropics and increases in the midlatitudes (Figs. 4a,b). Precipitation changes in the perturbed SST 

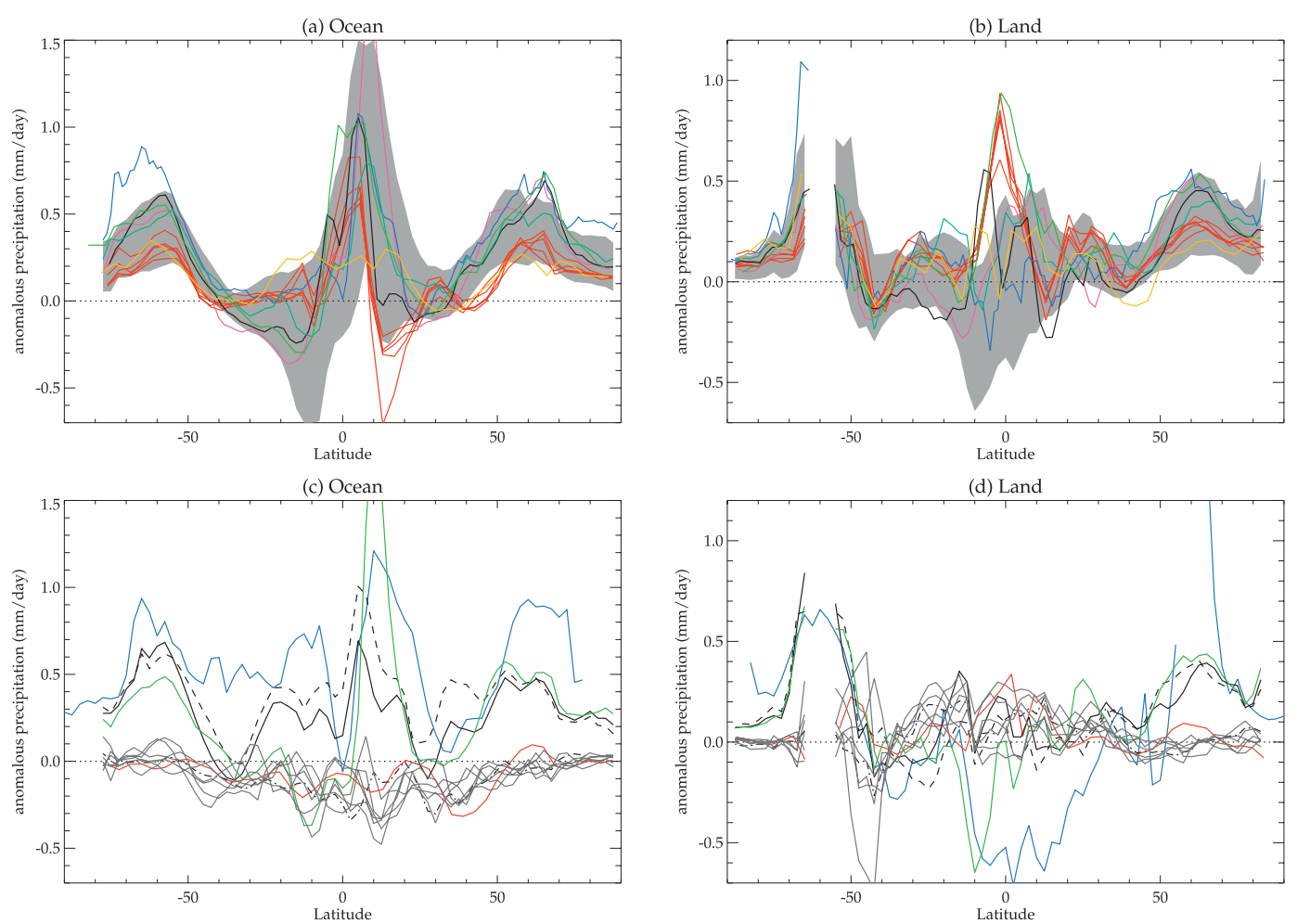

FIG. 4. Changes in GCM zonal-mean precipitation over (left) ocean and (right) land. (top) Slab model $2 \times \mathrm{CO}_{2}$ (equilibrium - control), QUMP (gray band is a 10\%-90\% range), CAM3 (red), CCCma (purple), ECHAM5 (pink), GFDL (black), HadGSM1 (blue), HadSM4 (turquoise), MIROC (green), and UIUC (orange). (bottom) The $+3 \mathrm{~K}$ SST perturbation only, HadGAM2 $+4 \mathrm{~K}$ (blue) and HadAM3 $+3 \mathrm{~K}$ (black dashed), $+3 \mathrm{~K} \mathrm{SST}+\left(2 \times \mathrm{CO}_{2}\right), \mathrm{HadAM} 3+3 \mathrm{~K}$ (black solid) and Hansen experiments, QUMP (gray), HadAM3 (black dotted-dashed), and CAM3 (red). Standard HadSM3 slab $2 \times \mathrm{CO}_{2}$ (equilibrium - control) (green) is included for comparison.

experiments appear quite different, although much of this will be due to nonuniform changes in SSTs in the slab experiments, which can lead to different changes in significant precipitation features, such as the intertropical convergence zone (Figs. 4c,d). HadGAM2 does show a decrease in tropical land precipitation of the kind we might expect where $\Delta A$ moves energy from ocean to land but HadAM3 does not. The HadAM $3+3 \mathrm{~K}+(2 \times$ $\mathrm{CO}_{2}$ ) experiment shows slightly smaller increases in ocean precipitation than the $+3 \mathrm{~K}$ experiment, as might be expected from the atmospheric opacity argument referenced above. However, the $+3 \mathrm{~K}+\left(2 \times \mathrm{CO}_{2}\right)$ changes do not look like the HadSM3 slab model, suggesting that differences in SST patterns between the perturbed SST and slab models dominate precipitation pattern differences. The Hansen experiments clearly show small decreases in ocean precipitation and increases in tropical land precipitation.

Circulation changes in the HadAM3 experiments are decomposed in Fig. 5. The Hansen experiment shows land regions of anomalous convection and ocean regions of anomalous subsidence (Fig. 5a). The $+3 \mathrm{~K}$ SST experiment shows the reverse: ocean regions of anomalous convection and land regions of anomalous subsidence. This is as might be expected from the heat transport hypothesis. Anomalous convection occurs over central Asia and subsidence occurs over significant areas of the ocean, however (Fig. 5b). Furthermore, although $\Delta A \sim 0$ in the $+3 \mathrm{~K}+\left(2 \times \mathrm{CO}_{2}\right)$ experiment, we see large circulation anomalies similar to those seen in the $+3 \mathrm{~K}$ experiment (Fig. 5c). This is most probably because the changes in circulation are largely linked to changes in surface temperatures rather than $\Delta A$. Figure $5 \mathrm{~d}$ shows the difference between the combined $+3 \mathrm{~K}+\left(2 \times \mathrm{CO}_{2}\right)$ experiment and the addition of the responses from the $+3 \mathrm{~K}$ and $2 \times \mathrm{CO}_{2}$ experiments. There are some regions of substantial nonlinearity, but the pattern is generally closer to zero than either Fig. 5a or Fig. 5b.

Changes in cloud radiative forcing (CRF) (all sky - clear sky radiative fluxes; Cess et al. 1990) in the HadAM3 experiments are shown in Fig. 6. CRF changes in the $+3 \mathrm{~K}$ experiment (Fig. 6b) are much larger than the initial adjustments shown by the $2 \times \mathrm{CO}_{2}$ experiment [although there are some large positive initial adjustments over land 

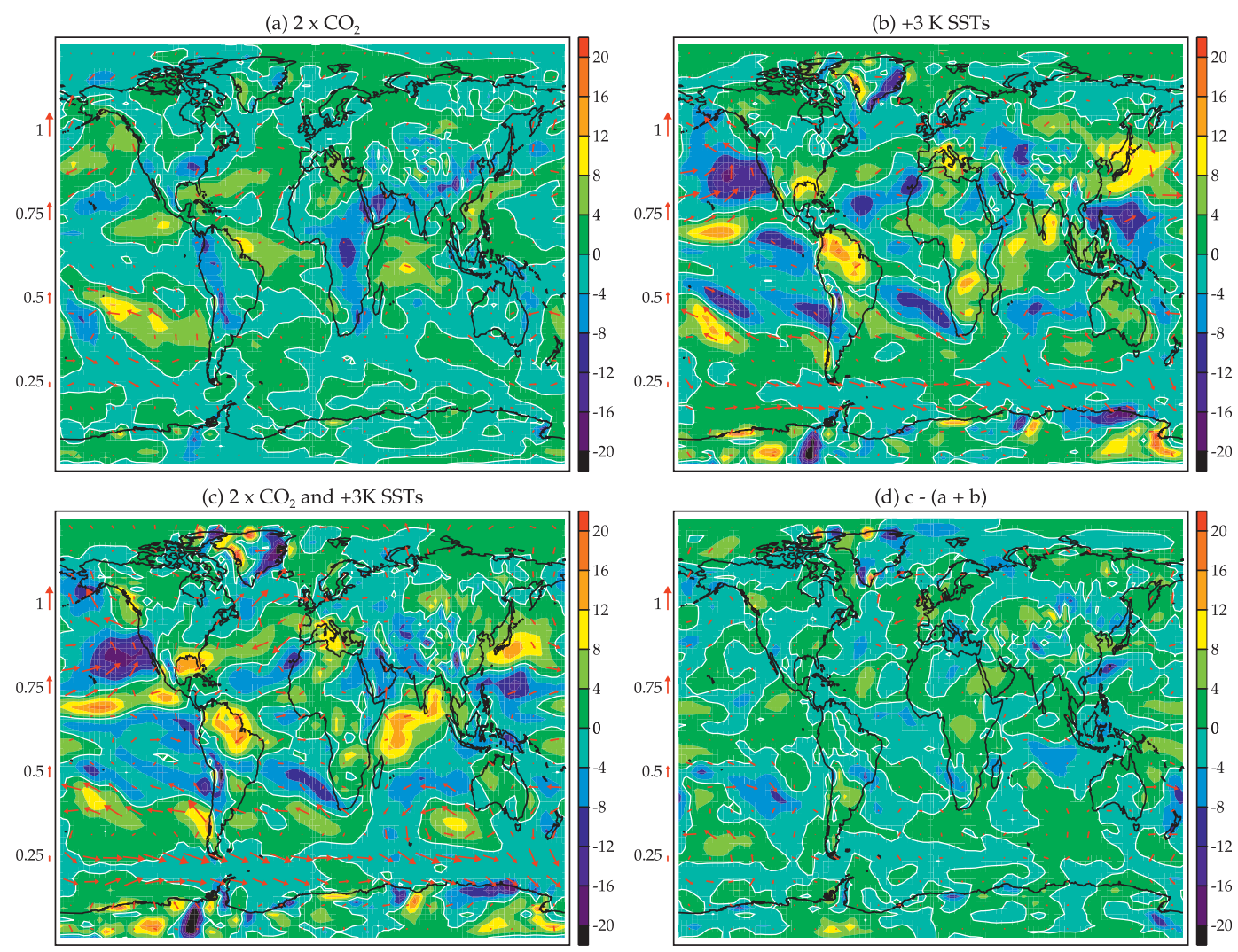

FIG. 5. Changes in atmospheric circulation in HadAM3 with respect to control conditions. The colored shading represents changes in vertical pressure velocity $\Omega$ at $500 \mathrm{hPa}$ in $\mathrm{Pa} \mathrm{s}^{-1}$ (right-hand scales). Positive numbers indicate regions of anomalous sinking; negative numbers indicate anomalous rising. The arrows represent changes in horizontal velocity in $\mathrm{m} \mathrm{s}^{-1}$ (left-hand scales). (a) $2 \times \mathrm{CO}_{2}$ Hansen experiment, (b) $+3 \mathrm{~K} \mathrm{SST}$ perturbation, (c) $+3 \mathrm{~K} \mathrm{SST}+$ $\left(2 \times \mathrm{CO}_{2}\right)$, and (d) $c-(a+b)$, showing departures from linearity when the climate responses to $2 \times \mathrm{CO}_{2}$ and $+3 \mathrm{~K}$ are separated.

regions because of cloud response to changes in stomatal conductance over boreal forest (Doutriaux-Boucher et al. 2009) (Fig. 6a)]. (The large negative CRF seen over the Arctic and Southern Oceans in Figs. 6b,c is a "cloud masking" artifact due to the interception of changes in clear-sky radiation over sea ice by clouds.) Hence, it is unsurprising that the difference between the combined $+3 \mathrm{~K}+\left(2 \times \mathrm{CO}_{2}\right)$ experiment (Fig. $\left.6 \mathrm{c}\right)$ and the sum of the individual $+3 \mathrm{~K}$ and $2 \times \mathrm{CO}_{2}$ experiments is small (Fig. 6d). In HadAM3, then, separating cloud feedbacks into $\Delta T_{G}$ dependent and forcing adjustment terms using perturbed SST and Hansen experiments does not cause substantial problems because of the nonlinearity of the response. This may not be the case in GCMs with more significant initial cloud adjustment to $\mathrm{CO}_{2}$ forcing (Gregory and Webb 2008).

Overall, changes in model precipitation and HadAM3 circulation and clouds associated with $\Delta A$ appear second order compared with the effects of changes in $\Delta T_{G}$, in stark contrast to the relationship between surface flux balance and $\Delta A$. We note that the HadAM3 response to the combined effect of $+3 \mathrm{~K}$ SSTs and $2 \times \mathrm{CO}_{2}$ is quite close to the linear sum of the responses to the two factors. This is true for precipitation, circulation, cloud radiative feedbacks, and $\Delta A$. Hence, although separating the GCM response into forcing and SST components could be considered unphysical, as the SST component does not exist in the absence of forcing in the real world, we find no mathematical pitfall. For a more detailed discussion of cloud, radiation, and humidity in fully coupled transient climate change, see Fasullo (2010).

\section{Discussion}

In our model simulations, $\Delta A$ is approximately what we expect from Eq. (4). Hence, the modeled climates behave as if atmospheric processes described by JGW08, CS09, and Dong et al. (2009) strongly couple both the land and ocean surfaces to the combined land and ocean heat reservoir. Equation (4) does tend to overestimate $\Delta A$ slightly 
(a) $2 \times \mathrm{CO}_{2}$

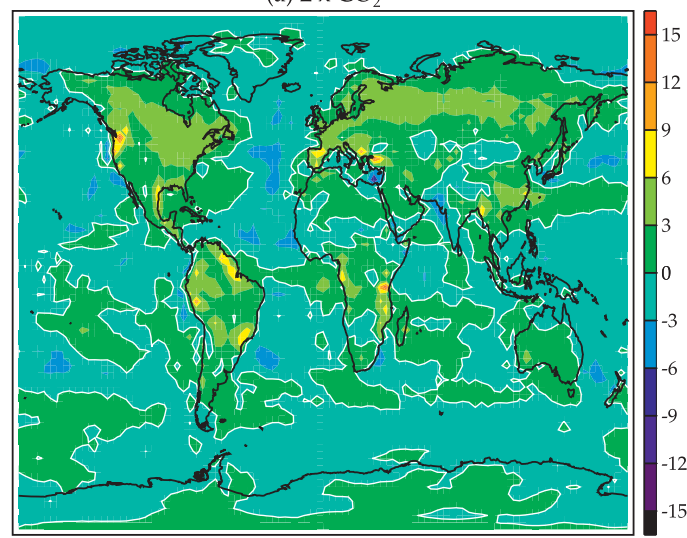

(c) $2 \times \mathrm{CO}_{2}$ and $+3 \mathrm{~K} \mathrm{SSTs}$

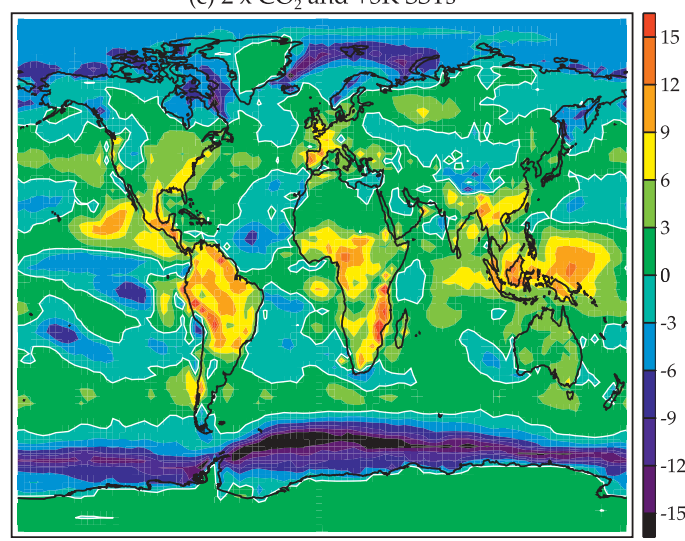

(b) +3 K SSTs

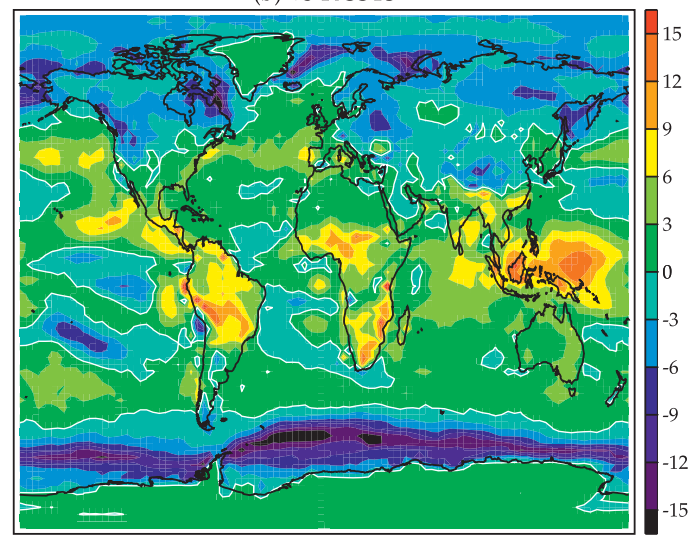

$(\mathrm{d}) \mathrm{c}-(\mathrm{a}+\mathrm{b})$

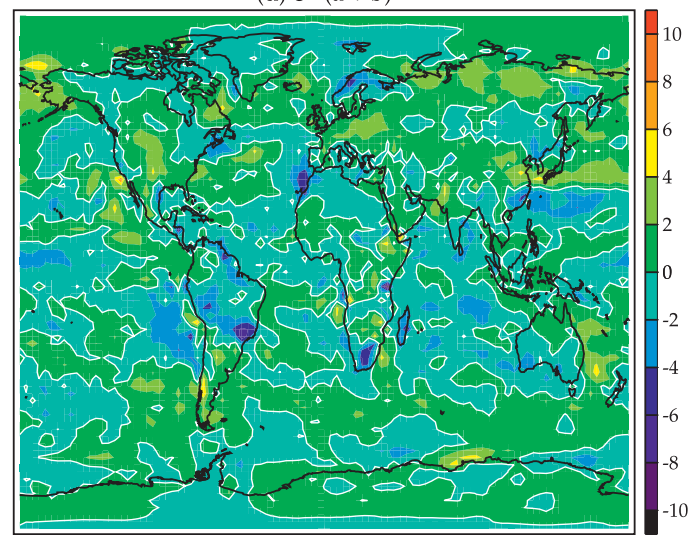

FIG. 6. Changes in cloud radiative forcing in $\mathrm{HadAM} 3$ with respect to control conditions in $\mathrm{W} \mathrm{m}^{-2}$ : (a) $2 \times \mathrm{CO}_{2}$ Hansen experiment, (b) $+3 \mathrm{~K}$ SST perturbation, (c) $+3 \mathrm{~K} \mathrm{SST}+\left(2 \times \mathrm{CO}_{2}\right)$, and (d) $c-(a+b)$, showing that climate responses to $2 \times \mathrm{CO}_{2}$ and $+3 \mathrm{~K}$ sum quite linearly (note the finer color scale on this panel).

near $\Delta T_{G}=0$ in the slab and Hansen experiments. This is consistent with the facts that $\Delta T_{L}$ increases slightly more than needed to maintain equilibrium $\phi$ during the initial phase following the application of forcing in the slab experiments and that $\Delta T_{L}$ is nonzero in the Hansen experiments (Fig. 2; see JGW08). Equivalently, the heat transported by $\Delta A$ is not quite sufficient to maintain constant $\phi$. Nevertheless, behavior is qualitatively as described by the heat transport hypothesis of LC07. We do not find evidence for our alternative nonenergetic teleconnection hypothesis, whereby teleconnections influence the local surface energy budget without significant advection of energy between land and ocean surfaces.

Although both hypotheses take the near-time-invariant ratio of $\phi$ as axiomatic, distinguishing between the two is important. Under the heat transport hypothesis, radiative forcing over land and ocean are equally influential; under the nonenergetic teleconnection hypothesis, radiative forcing over land has little effect. Hence, we find with Forster et al. (2000) and Boer and Yu (2003) that modeled surface temperature changes are quite well described as local responses to global mean forcings. In common with CS09 and D09, we find that ocean and land climate change are inseparable and that adherence to $\phi$ tends to override any other consideration in a variety of different model runs. We do not find evidence that radiative forcing over land has little effect, however. This is potentially important for understanding past and future climate change when we consider that the majority of anthropogenic aerosol forcing occurs over land (Forster et al. 2007).

Surface temperature, precipitation, cloud radiative forcing, and atmospheric circulation change look similar in slab experiments, perturbed SST experiments, and perturbed SST experiments whose TOA flux anomaly has been balanced by the application of radiative forcing; energy fluxes at the surface are very different. Immediately after a doubling of $\mathrm{CO}_{2}$ concentration, slab experiments show a land-to-ocean energy transport anomaly that prevents $\Delta T_{L}$ from increasing rapidly and maintains near-time-invariant $\phi$ (Fig. 1b). As global mean temperature increases and climate approaches its new 
equilibrium, $\Delta A$ decreases until it reaches a small value of either sign, dependent on the GCM considered (Fig. 1c). Conversely, where we impose $\Delta T_{O}$ in a perturbed SST experiment, energy flows in the opposite direction-from ocean to land-causing land warming and establishing time-invariant $\phi$. Large $\Delta A$ continues to flow after temperatures have stabilized (Fig. 1d). In our HasdAM3 +3K SST experiment, where global mean temperature change is similar to that found at the perturbed equilibrium in the $2 \times \mathrm{CO}_{2}$ slab runs, net radiation to space is around $4.5 \mathrm{~W} \mathrm{~m}^{-2}$ globally. Approximately $6.5 \mathrm{~W} \mathrm{~m}^{-2}$ is lost by the ocean surface, which we expect from $\Delta U_{O} \sim \Delta N_{G}$ l $(1-f)$ [see section $2 \mathrm{~b}(2)$ ]. We can bring the model almost to equilibrium by doubling $\mathrm{CO}_{2}$ globally, reducing TOA heat loss to space to about $0.5 \mathrm{~W} \mathrm{~m}^{-2}$, as we do in the $+3 \mathrm{~K} \mathrm{SST}+\left(2 \times \mathrm{CO}_{2}\right)$ HadAM3 experiment. If we had instead doubled $\mathrm{CO}_{2}$ over the ocean alone, then this would lead to a global mean forcing of about 2.5-3 $\mathrm{W} \mathrm{m}^{-2}$, insufficient to correct TOA imbalance. The forcing above the ocean itself would be about $3.5-4 \mathrm{~W} \mathrm{~m}^{-2}$, insufficient to balance ocean surface heat loss.

These results suggest that radiative forcing over land is important. However, a more persuasive test might be to compare the modeled responses where forcing is applied globally, only over ocean, and only over land. Forster et al. (2000) carried out such experiments using an intermediate complexity GCM and found very little difference in global climate sensitivity for either $\mathrm{CO}_{2}$ or solar forcing (their Tables 1 and 2), meaning that surface temperature responses were primarily dependent on the magnitude of global mean forcing and not forcing location. Hence, they found that doubling $\mathrm{CO}_{2}$ over ocean alone produced a global mean surface temperature response of about a factor of $1-f$ the size found when $\mathrm{CO}_{2}$ was doubled globally.

Still, the perturbed land temperature experiments of D09 are apparently inconsistent with our GCM runs and those of Forster et al. (2000). Where land temperatures were increased by $1 \mathrm{~K}$, SSTs only increased by $0.2 \mathrm{~K}$. This suggests that SSTs are little affected by land temperature change. Conversely, where land temperatures were fixed at control values and atmospheric $\mathrm{CO}_{2}$ concentration was doubled (a fixed land Hansen experiment), the SST response was only $1 \mathrm{~K}$, as opposed to $3 \mathrm{~K}$ where land temperatures were free to change. Hence, there is apparently a large land effect on ocean surface temperatures in this case. Because D09's perturbed land temperature experiment has only been run for $20 \mathrm{yr}$, SSTs may not have reached steady state, as the ocean model is a $500 \mathrm{~m}$ deep mixed layer.

We emphasize that our conclusions do not contradict the hypothesis that SSTs can control shorter-term interannual variations in land temperatures, such as those due to natural variability, or that patterns of SST change are important to patterns of land temperature change in general (Cash et al. 2005; Hoerling et al. 2008). In fact, we reconfirm these ideas. In our GCM experiments, imposing changes in SST forces changes in land temperatures that maintain $\phi$ close to the value seen in radiatively forced experiments.

In contrast to its large effect on surface fluxes, $\Delta A$ has relatively small impacts on precipitation, circulation, and cloud in the GCMs we analyze. At $\Delta T_{G}=0$, there are small forcing-dependent increases in land precipitation and decreases in ocean precipitation in the slab and Hansen experiments. We expect this in the tropics, as exporting energy from land to ocean should be associated with anomalous convection over land and anomalous subsidence over ocean. Precipitation in the perturbed SST experiments does appear different from that in slab $2 \times$ $\mathrm{CO}_{2}$ slab equilibria, as might be expected where $\Delta A$ exists. However, in the HadAM $3+3 \mathrm{~K} \mathrm{SST}+\left(2 \times \mathrm{CO}_{2}\right)$ experiment, precipitation change is much more similar to the perturbed SST-only experiment than to slab equilibria, suggesting that the different patterns of SST perturbation in perturbed SST and slab experiments are much more important to changes in precipitation. In HadAM3, there are also impacts on circulation and CRF at $\Delta T_{G}=0$, but the effect of changes in surface temperature dominates. We find little sign of nonlinearity when we add the responses from the separate $+3 \mathrm{~K} \mathrm{SST}$ and $2 \times \mathrm{CO}_{2}$ experiments and compare them to the combined $+3 \mathrm{~K} \mathrm{SST}+\left(2 \times \mathrm{CO}_{2}\right)$ experiment (the same may not be the case for models that suffer larger cloud adjustment to $\mathrm{CO}_{2}$ forcing than HadAM3, as described by Gregory and Webb (2008)]. Although we have no relevant data for other models, we note that Deser and Phillips (2009) came to a similar conclusion for CAM3 simulations of 1950-2000. We do not, therefore, raise an objection to projects, such as CFMIP2, that make this decomposition.

\section{Summary}

We find that a range of idealized GCM experiments show an approximately time invariant ratio, $\phi$, of mean land surface temperature change, $\Delta T_{L}$, to mean ocean surface temperature change, $\Delta T_{O}$, at equilibrium, during slab spinup climate change and in a fully coupled transient run, in common with previous work (Manabe et al. 1991; Huntingford and Cox 2000; Sutton et al. 2007; LC07; JGW08). We confirm also that "perturbed SST" GCM experiments, in which climate is changed by imposing $\Delta T_{O}$, produce almost the same $\phi$ as slab model experiments forced with changes in atmospheric $\mathrm{CO}_{2}$ concentration (JGW08; CS09; D09). Adding a globally uniform 
increase in $\mathrm{CO}_{2}$ that is almost in equilibrium with imposed $\Delta T_{O}$ only increases $\Delta T_{L}$ a little.

We find that the dominant atmospheric processes coupling land and ocean surface temperature change transport heat between land and ocean surfaces. This makes sense in light of large climatological atmospheric heat transports that tend to homogenize surface temperatures and that cause heat taken up at the top of atmosphere over the seasonal cycle to be almost entirely absorbed by the ocean (Shin et al. 2006; Fasullo and Trenberth 2008a,b). We do not find support for a dominant role for an alternate idea whereby ocean surface climate change manipulates the atmosphere over land, causing land surface heating without significant ocean-to-land surface heat transport. This does not rule out any role for "nonenergetic teleconnections," however.

In our GCM experiments, when climate change is driven by radiative forcing, initially a heat transport anomaly moves heat from land to ocean, preventing the land from warming rapidly and maintaining $\phi$ near its equilibrium value. As equilibrium is approached, the anomaly tends to a small value. When climate change is driven by perturbing SSTs, anomalous heat is transported from ocean to land, warming the land. In steady state, the heat transport anomaly remains large, effectively replicating the radiative forcing that would be seen over land in a radiatively forced experiment. We find that heat transport anomalies in the above situations can be approximated using a simple equation developed from LC07. These ideas may be relevant to heat transport anomalies in the real climate system, although we note that this may not be so on short time scales if the ocean is able to show a smaller effective heat capacity to rapid changes in forcing.

Heat loss to space in the perturbed SST experiments is approximately that which would be balanced by global radiative forcing in a radiatively forced experiment with the same change in global mean temperature. Hence, per square meter, radiative forcing over land appears to be as important as radiative forcing over ocean. It does not appear to be the case that radiative forcing over land is balanced merely by feedbacks related to the small increase in land temperature that occurs in a perturbed SST experiment when radiative forcing is applied. This conclusion is consistent with the idealized simulations of Forster et al. (2000), who found that the global mean temperature response depends on global mean forcing and is more or less independent of whether the forcing is applied globally, over ocean only, or over land only. Therefore, we rediscover the behavior described by Forster et al. (2000), Boer and Yu (2003), and Joshi et al. (2003): for quite globally uniform radiative forcings, land and ocean climate responses depend on local climate response and global mean forcing.
In contrast to its significant effects at the surface, landto-ocean heat transport has quite minor impacts on precipitation, circulation, and cloud in our GCM runs. The dominant effects in the $+3 \mathrm{~K}$ SST simulation appear to be due to changes in surface temperature rather than landto-ocean heat transport. There is also little sign of nonlinearity when we add the responses from the separate $+3 \mathrm{~K} \mathrm{SST}$ and $2 \times \mathrm{CO}_{2}$ experiments and compare them to the combined $+3 \mathrm{~K} \mathrm{SST}+\left(2 \times \mathrm{CO}_{2}\right)$ experiment. Hence, we do not see a problem with decomposing model responses into temperature and forcing-dependent components, as is sometimes done in model intercomparison projects. Finally, we note that atmospheric heat transports that equalize imbalances in forcing are not confined to controlling land-ocean contrasts. Yoshimori and Broccoli (2008) found that applying hemispherically asymmetric forcings to a GCM tended to produce cross-equatorial energy transports that equalized the radiative effect at the surface. It does appear, however, that forcing imbalances are equalized more efficiently zonally rather than meridionally (Shindell and Faluvegi 2009).

Acknowledgments. We thank John Fasullo and five anonymous reviewers for their reviews. We acknowledge the modeling groups for making their simulations available for analysis, the Program for Climate Model Diagnosis and Intercomparison (PCMDI) for collecting and archiving the CMIP3 and CFMIP model output, and the WCRP's Working Group on Coupled Modelling (WGCM) for organizing the model data analysis activity. The WCRP CMIP3 and CFMIP multimodel datasets are supported by the Office of Science, U.S. Department of Energy. The CAM3 integrations were performed on the Lightning SMP cluster maintained by NCAR. FHL and MJW were supported by the Joint DECC, Defra, and MoD Integrated Climate Programme-DECC/Defra (Programme Element GA01101) and MoD (Programme Element CBC/2B/0417_Annex C5). MMJ was supported by NCAS-Climate.

\section{APPENDIX}

\section{Calculation of Land-to-Ocean Heat Transport}

The difference between the TOA net downward radiative flux and the surface net downward radiative and turbulent flux above the ocean alone is the rate of heat storage by the atmosphere above the ocean, $\Delta U_{\mathrm{OA}}$, plus its rate of heat loss to the atmosphere above the land, $-\Delta A /(1-f)$ :

$$
\frac{-\Delta A}{1-f}=\Delta N_{O}-\Delta U_{O}-\Delta U_{\mathrm{OA}},
$$


where $\Delta N_{O}$ is net downward TOA flux over the ocean. Similarly, the difference between net downward TOA and surface fluxes over land alone is the rate of heat storage by the atmosphere above the land, $\Delta U_{\mathrm{LA}}$, plus its rate of heat loss to the atmosphere above the ocean, $\Delta A / f$ :

$$
\frac{\Delta A}{f}=\Delta N_{L}-\Delta U_{L}-\Delta U_{\mathrm{LA}},
$$

where $\Delta N_{L}$ is net downward TOA flux over the land. Because changes in atmospheric heat storage are fairly insignificant on annual and longer time scales, we could assume that $\Delta U_{\mathrm{OA}, \mathrm{LA}}$, which we cannot calculate from atmospheric energy budget analysis, are zero. Doing so yields similar values of $\Delta A$ in Eqs. (A1) and (A2). Alternatively, we can estimate the global mean atmospheric heat uptake $\Delta U_{\mathrm{GA}}$ from

$$
\Delta U_{\mathrm{GA}}=\Delta N_{G}-\Delta U_{G},
$$

where $\Delta U_{G}$ is the global mean surface heat uptake. Approximating $\Delta U_{\mathrm{OA}, \mathrm{LA}} \sim \Delta U_{\mathrm{GA}}$ allows estimates of $\Delta A$ from Eqs. (A1) and (A2) that differ by less than $0.1 \mathrm{~W} \mathrm{~m}^{-2}$, apart from in ECHAM5, where estimates differ by less than $0.2 \mathrm{~W} \mathrm{~m}^{-2}$. The fraction of $\Delta N_{G}$ absorbed by the atmosphere, $\Delta U_{\mathrm{GA}} / \Delta N_{G}$, is given in Table 1. This represents not only heat taken up by the atmosphere but may also contain a component due to model errors that leads to the nonconservation of energy.

\section{Components of $\Delta A$}

Subtracting Eq. (A1) from Eq. (A2) yields

$\Delta A=f(1-f)\left(\Delta N_{L}-\Delta N_{O}+\Delta U_{O}-\Delta U_{L}\right)$.

To calculate the component of $\Delta A$ balanced by TOA fluxes, $\Delta A_{\mathrm{TOA}}$, we neglect the land and ocean heat uptake terms and find

$$
\Delta A_{\mathrm{TOA}}=f(1-f)\left(\Delta N_{L}-\Delta N_{O}\right)
$$

Note that the LC07 heat transport, Eq. (3), is almost the component of Eq. (A4) balanced by surface fluxes, $f(1-f)$ $\left(\Delta U_{O}-\Delta U_{L}\right)$

\section{REFERENCES}

Allen, M. R., and W. J. Ingram, 2002: Constraints on future changes in climate and the hydrologic cycle. Nature, 419, 224-232.

Andrews, T., P. M. Forster, and J. M. Gregory, 2009: A surface energy perspective on climate change. J. Climate, 22, 2557-2570.

Beltrami, H., J. E. Smerdon, H. N. Pollack, and S. Huang, 2002: Continental heat gain in the global climate system. Geophys. Res. Lett., 29, 1167, doi:10.1029/2001GL014310.
Boer, G. J., and B. Yu, 2003: Climate sensitivity and response. Climate Dyn., 20, 415-429.

Brown, R. G., and C. S. Bretherton, 1997: A test of the strict quasiequilibrium theory on long time and space scales. J. Atmos. Sci., 54, 624-638.

Cash, B. A., E. K. Schneider, and L. Bengtsson, 2005: Origin of regional climate differences: Role of boundary conditions and model formulation in two GCMs. Climate Dyn., 25, 709-723.

Cess, R. D., and Coauthors, 1990: Intercomparison and interpretation of climate feedback processes in 19 atmospheric general circulation models. J. Geophys. Res., 95, 16 601-16 615.

Chiang, J. C. H., and A. H. Sobel, 2002: Tropical tropospheric temperature variations caused by ENSO and their influence on the remote tropical climate. J. Climate, 15, 2616-2631.

Collins, W. D., and Coauthors, 2006: The formulation and atmospheric simulation of the Community Atmosphere Model Version 3 (CAM3). J. Climate, 19, 2144-2161.

Compo, G. P., and P. D. Sardeshmukh, 2009: Oceanic influences on recent continental warming. Climate Dyn., 32, 333-342, doi:10.1007/s00382-008-0448-9.

Curry, J. A., and P. J. Webster, 1999: Ocean surface exchanges of heat and freshwater. Thermodynamics of Atmospheres and Oceans, J. R. Holton, Ed., International Geophysics Series, Vol. 65, Academic Press, 247-265.

Deser, C., and A. S. Phillips, 2009: Atmospheric circulation trends, 1950-2000: The relative roles of sea surface temperature forcing and direct atmospheric radiative forcing. J. Climate, 22, 396-413.

Dommenget, D., 2009: The ocean's role in continental climate variability and change. J. Climate, 22, 4939-4952.

Dong, B., J. M. Gregory, and R. T. Sutton, 2009: Understanding land-sea warming contrast in response to increasing greenhouse gases. Part I: Transient adjustment. J. Climate, 22, 3079-3097.

Doutriaux-Boucher, M., M. J. Webb, J. M. Gregory, and O. Boucher, 2009: Carbon dioxide induced stomatal closure increases radiative forcing via a rapid reduction in low cloud. Geophys. Res. Lett., 36, L02703, doi:10.1029/2008GL036273.

Ellis, J. S., T. H. Vonder Haar, S. Levitus, and A. H. Oort, 1978: The annual variation in the global heat balance of the earth. J. Geophys. Res., 83, 1958-1962.

Fasullo, J. T., 2010: Robust land-ocean contrasts in energy and water cycle feedbacks. J. Climate, 23, 4677-4693.

— , and K. E. Trenberth, 2008a: The annual cycle of the energy budget. Part I: Global mean and land-ocean exchanges. J. Climate, 21, 2297-2312.

— Meridional structures and poleward transports. J. Climate, 21, 2313-2325.

Forster, P. M., M. Blackburn, R. Glover, and K. P. Shine, 2000: An examination of climate sensitivity for idealised climate change experiments in an intermediate general circulation model. Climate Dyn., 16, 833-849.

—, and Coauthors, 2007: Changes in atmospheric constituents and in radiative forcing. Climate Change 2007: The Physical Science Basis, S. Solomon et al., Eds., Cambridge University Press, 129-234.

Gordon, C., C. Cooper, C. A. Senior, H. Banks, J. M. Gregory, T. C. Johns, J. F. B. Mitchell, and R. A. Wood, 2000: The simulation of SST, sea ice extents and ocean heat transports in a version of the Hadley Centre coupled model without flux adjustments. Climate Dyn., 16, 147-168.

Gregory, J. M., and M. J. Webb, 2008: Tropospheric adjustment induces a cloud component in $\mathrm{CO}_{2}$ forcing. J. Climate, 21, 58-71. 
— , and Coauthors, 2004: A new method for diagnosing radiative forcing and climate sensitivity. Geophys. Res. Lett., 31, L03205, doi:10.1029/2003GL018747.

Hansen, J., and Coauthors, 2002: Climate forcings in Goddard Institute for Space Studies SI2000 simulations. J. Geophys. Res., 107, 4347, doi:10.1029/2001JD001143.

_- and Coauthors, 2005: Efficacy of climate forcings. J. Geophys. Res., 110, D18104, doi:10.1029/2005JD005776.

Hoerling, M., A. Kumar, J. Eischeid, and B. Jha, 2008: What is causing the variability in global mean land temperature? Geophys. Res. Lett., 35, L23712, doi:10.1029/2008GL035984.

Hulme, M., T. J. Osborn, and T. C. Johns, 1998: Precipitation sensitivity to global warming: Comparison of observations with HadCM2 simulations. Geophys. Res. Lett., 25, 3379-3382.

Huntingford, C., and P. M. Cox, 2000: An analogue model to derive additional climate change scenarios from existing GCM simulations. Climate Dyn., 16, 575-586.

Joshi, M. M., and J. M. Gregory, 2008: The dependence of the land-sea contrast in surface climate response on the nature of the forcing. Geophys. Res. Lett., 35, L24802, doi:10.1029/2008GL036234.

_ K. P. Shine, M. Ponater, N. Stuber, R. Sausen, and L. Li, 2003: A comparison of climate response to different radiative forcings in three general circulation models: Towards an improved metric of climate change. Climate Dyn., 20, 843-854.

— J. M. Gregory, M. J. Webb, D. M. H. Sexton, and T. C. Johns, 2008: Mechanisms for the land/sea warming contrast exhibited by simulations of climate change. Climate Dyn., 30, 455-465.

Lambert, F. H., and J. C. H. Chiang, 2007: Control of land-ocean temperature contrast by ocean heat uptake. Geophys. Res. Lett., 34, L13704, doi:10.1029/2007GL029755.

Manabe, S., M. J. Spelman, and R. J. Stouffer, 1991: Transient responses of a coupled ocean-atmosphere model to gradual changes of atmospheric $\mathrm{CO}_{2}$. Part I: Annual mean response. J. Climate, 4, 785-818.

Martin, G. M., M. A. Ringer, V. D. Pope, A. Jones, C. Dearden, and T. J. Hinton, 2006: The physical properties of the atmosphere in the new Hadley Centre global environmental model (HadGEM1). Part I: Model description and global climatology. J. Climate, 19, 1274-1301.

Mitchell, J. F. B., C. A. Wilson, and W. M. Cunnington, 1987: On $\mathrm{CO}_{2}$ climate sensitivity and model dependence of results. Quart. J. Roy. Meteor. Soc., 113, 293-322.

Murphy, J. M., 1995: Transient response of the Hadley Centre coupled ocean-atmosphere model to increasing carbon dioxide. Part III: Analysis of global-mean response using simple models. J. Climate, 8, 496-514.

— D. M. H. Sexton, D. N. Barnett, G. S. Jones, M. J. Webb, M. Collins, and D. J. Stainforth, 2004: Quantification of modelling uncertainties in a large ensemble of climate change simulations. Nature, 430, 768-772.

Pope, V. D., M. L. Gallani, P. R. Rowntree, and R. A. Stratton, 2000: The impact of new physical parametrizations in the
Hadley Centre climate model: HadAM3. Climate Dyn., 16, 123-146.

Rayner, N. A., E. B. Horton, D. E. Parker, C. K. Folland, and R. B. Hackett, 1996: Version 2.2 of the Global Sea-Ice and Sea Surface Temperature data set, 1903-1994. Hadley Centre Climate Research Tech. Note 74, 50 pp.

Shin, H.-J., I.-U. Chung, H.-J. Kim, and J.-W. Kim, 2006: Global energy cycle between land and ocean in the simulated 20th century climate systems. Geophys. Res. Lett., 33, L14702, doi:10.1029/2006GL025977.

Shindell, D., and G. Faluvegi, 2009: Climate response to regional radiative forcing during the twentieth century. Nat. Geosci., 2, 294-300.

Smerdon, J. E., and M. Stieglitz, 2006: Simulating heat transport of harmonic temperature signals in the earth's shallow subsurface: Lower-boundary sensitivities. Geophys. Res. Lett., 33, L14402, doi:10.1029/2006GL026816.

Stevens, M. B., J. E. Smerdon, J. F. González-Rouco, M. Stieglitz, and $\mathrm{H}$. Beltrami, 2007: Effects of bottom boundary placement on subsurface heat storage: Implications for climate model simulations. Geophys. Res. Lett., 34, L02702, doi:10.1029/ 2006 GL028546.

Sutton, R. T., B. Dong, and J. M. Gregory, 2007: Land/sea warming ratio in response to climate change: IPCC AR4 model results and comparison with observations. Geophys. Res. Lett., 34, L02701, doi:10.1029/2006GL028164.

Trenberth, K. E., and A. Solomon, 1994: The global heat balance: Heat transports in the atmosphere and ocean. Climate Dyn., 10, 107-134.

_ L. L. Smith, T. Qian, A. Dai, and J. Fasullo, 2007: Estimates of the global water budget and its annual cycle using observational and model data. J. Hydrometeor., 8, 758-769.

Webb, M. J., and Coauthors, 2006: On the contribution of local feedback mechanisms to the range of climate sensitivity in two GCM ensembles. Climate Dyn., 27, 17-38.

Welch, B. L., 1947: The generalization of "student's" problem when several different population variances are involved. $B i$ ometrika, 34, 28-35.

Williams, K. D., A. Jones, D. L. Roberts, C. A. Senior, and M. J. Woodage, 2001a: The response of the climate system to the indirect effects of anthropogenic sulfate aerosol. Climate Dyn., 17, 845-856.

_ C. A. Senior, and J. F. B. Mitchell, 2001b: Transient climate change in the Hadley Centre models: The role of physical processes. J. Climate, 14, 2659-2674.

Yang, F., A. Kumar, M. E. Schlesinger, and W. Wang, 2003: Intensity of hydrological cycles in warmer climates. J. Climate, 16, 2419-2423.

Yoshimori, M., and A. J. Broccoli, 2008: Equilibrium response of an atmosphere-mixed layer ocean model to different radiative forcing agents: Global and zonal mean response. J. Climate, 21, 4399-4423. 